\title{
Neural Signatures of Autism Spectrum Disorders: Insights into Brain Network Dynamics
}

\author{
Leanna M Hernandez ${ }^{1,2,3}$, Jeffrey D Rudie ${ }^{3,4}$, Shulamite A Green ${ }^{2,3,5}$, Susan Bookheimer ${ }^{2,4,5}$ and \\ Mirella Dapretto ${ }^{\star 2,3}$ \\ ${ }^{1}$ Interdepartmental Neuroscience Program, University of California, Los Angeles, Los Angeles, CA, USA; ${ }^{2}$ Department of \\ Psychiatry and Biobehavioral Sciences, University of California, Los Angeles, Los Angeles, CA, USA; ${ }^{3}$ Ahmanson-Lovelace \\ Brain Mapping Center, University of California, Los Angeles, Los Angeles, CA, USA; ${ }^{4}$ David Geffen School of Medicine, \\ University of California, Los Angeles, Los Angeles, CA, USA; ${ }^{5}$ Department of Psychology, University of California, \\ Los Angeles, Los Angeles, CA, USA
}

\begin{abstract}
Neuroimaging investigations of autism spectrum disorders (ASDs) have advanced our understanding of atypical brain function and structure, and have recently converged on a model of altered network-level connectivity. Traditional task-based functional magnetic resonance imaging (MRI) and volume-based structural MRI studies have identified widespread atypicalities in brain regions involved in social behavior and other core ASD-related behavioral deficits. More recent advances in MR-neuroimaging methods allow for quantification of brain connectivity using diffusion tensor imaging, functional connectivity, and graph theoretic methods. These newer techniques have moved the field toward a systems-level understanding of ASD etiology, integrating functional and structural measures across distal brain regions. Neuroimaging findings in ASD as a whole have been mixed and at times contradictory, likely due to the vast genetic and phenotypic heterogeneity characteristic of the disorder. Future longitudinal studies of brain development will be crucial to yield insights into mechanisms of disease etiology in ASD sub-populations. Advances in neuroimaging methods and large-scale collaborations will also allow for an integrated approach linking neuroimaging, genetics, and phenotypic data.
\end{abstract}

Neuropsychopharmacology Reviews (2015) 40, I7I-189; doi:I0.1038/npp.2014.172; published online 6 August 2014

\section{INTRODUCTION}

Autism spectrum disorders (ASDs) are heritable neurodevelopmental disorders (eg, Bailey et al, 1995; Nordenbæk et al, 2014) in which manifestations of behavioral symptomology vary widely in severity. Core behavioral deficits associated with the disorder include impairments in social communication and social interactions, along with the presence of repetitive patterns of behavior, restricted interests, and/or altered sensory responsivity to external stimuli (American Psychiatric Association, 2013). Although these deficits serve as defining criteria on which diagnoses are currently based, not all individuals on the ASD spectrum display each symptom, and there is a broad spectrum of social, emotional, and cognitive impairment among diagnosed individuals.

The last decade has seen the rate of ASD diagnosis rise to an estimated 1 in every 68 children (Center for Disease Control, 2014), making early diagnosis and effective treat-

\footnotetext{
${ }^{*}$ Correspondence: Dr M Dapretto, Department Psychiatry and Biobehavioral Sciences, Ahmanson-Lovelace Brain Mapping Center, 660 Charles Young Drive South, Los Angeles, CA 90095, USA, Tel: +1 310206 2960, Fax: +1 310794 7406, E-mail: mirella@ucla.edu

Received 9 June 2014; revised 2 July 2014; accepted 3 July 2014; accepted article preview online 11 July 2014
}

ment a critical public health concern. However, the heterogeneity present in individuals with ASD makes discerning a singular neuropathological cause and developing effective treatments very challenging. Thus, a major goal of ASD research is to understand the neurobiological underpinnings of ASD from a multidimensional perspective-investigating how brain anatomy, function, and connectivity are altered in ASD and how they vary among affected individuals.

Over the past two decades, major advances in magnetic resonance (MR)-based structural and functional neuroimaging have greatly enhanced our understanding of brain differences in ASD. In structural brain imaging, newer analysis approaches including cortical thickness mapping, voxel-based morphometry (VBM), diffusion tensor imaging (DTI), and the application of these methods in younger subject populations or in longitudinal studies have led to more specific and dynamic models of abnormal brain development in autism. In functional neuroimaging, the field has moved beyond task-based functional activation studies, which were typically limited to high-functioning children and adults. New acquisition methods, such as resting state functional MR imaging (fMRI), and novel data-analytic approaches now allow for the study of largescale functional brain networks and connectivity in much 
younger populations including toddlers and infants at high risk for developing autism. Finally, the integration of both structural and functional imaging with genetic risk and behavioral data has driven the field toward a better understanding of gene-brain-behavior pathways in autism. Together, the corpus of imaging studies in autism have led to an emerging model of abnormal developmental connectivity, a dynamic model that accounts for both genetic liability and environmental influences that shape early brain development. In this review, we will present data from these major new domains of MR imaging work-structural MRI (sMRI), functional MRI, imaging-genetics, and connectivity studies, focusing on developmental trajectories and ultimately converging on a model of abnormal brain development in autism.

\section{STRUCTURAL NEUROIMAGING (sMRI) STUDIES}

\section{Structural Volume Assessment (Volumetry)}

Historically, some of the first efforts to characterize the neural correlates of ASD investigated differences in largescale brain structures between affected individuals and neurotypical controls. Initial evidence for altered brain structure and enlarged brain volume in ASD came from postmortem investigations (eg, Bailey et al, 1998). The development of non-invasive MRI techniques subsequently allowed for more detailed study of brain volumes in specific brain regions across the lifespan in otherwise healthy individuals. The primary underlying hypothesis driving such studies has been that abnormalities in specific brain structures early in development, often assumed to be decreased gray matter volume, may pinpoint a causal neuroanatomical basis for behavioral features in autism.

Traditional methods for assessing volume rely on manual tracing of regions of interest (ROIs), often defined by macro-structural features (ie, hemispheres, lobes, subcortical areas, major gyri, and sulci) easily visible on high-resolution sMRI images. In toddlers with ASD, one of the most consistently reported global-level findings in sMRI is an increase in total brain volume of $5-10 \%$ compared with locally recruited neurotypical children (eg, Carper et al, 2002; Courchesne et al, 2001; Hazlett et al, 2005; Sparks et al, 2002; for a review, see Amaral et al, 2008 and Stanfield et al, 2008). Analyses of brain development suggest that brain volume is normal at birth, diverging from typical trajectories during early childhood when children with ASD experience a period of brain overgrowth (reflected by enlarged total brain volume); this period is then followed by a plateau in volumetric changes during adolescence, ultimately leading to adult brain volumes that fall within range of typically developing controls (Courchesne et al, 2001, 2007). However, there is also some evidence for enlarged total brain volume in adolescence and adulthood (Freitag et al, 2009; Hazlett et al, 2006).

In addition to enlarged total cerebral volume, ASD is characterized by atypical gray and white matter (WM) volume in discrete brain structures (see recent reviews by Amaral et al, 2008; Chen et al, 2011; Stanfield et al, 2008; Steigler et al, 2011). The nature of these differences, unfortunately, has varied substantially across studies. An early finding in children, adolescents, and adults with autism reported marked decrease in volume of the cerebellar vermis (Courchesne et al, 1988, 1994); however, many of these subjects were low functioning. Several studies subsequently found that after controlling for or matching IQ cerebellar differences were no longer apparent (Levitt et al, 1999; Manes et al, 1999; Piven et al, 1992), suggesting that reduced cerebellar vermis may relate to intellectual dysfunction but not necessarily core features of autism. In other brain areas, both increases and decreases in volumes have been reported in many regions including the frontal cortex (eg, Hyde et al, 2010; McAlonan et al, 2005), superior temporal sulcus (eg, Boddeart et al, 2004), inferior parietal lobule (eg, Hadjikhani et al, 2006), cingulate, and fusiform gyrus (eg, Bonilha et al, 2008) - many areas known to have a role in social cognition.

\section{Voxel-Based Morphometry}

Recent advances in postimaging processing methods allow for comparisons of gray and WM density and volume on a voxel-by-voxel basis, referred to as VBM. Unlike traditional ROI-based volume analyses, VBM allows for whole-brain comparisons of gray and WM volume between two groups. Results of these studies comparing individuals with ASD to neurotypical individuals have been extremely mixed, often reporting heterogeneous and at times contradictory results (for a review, see Chen et al, 2011). In a recent meta-analysis of VBM studies covering a wide age range of individuals with ASD, Nickl-Jockschat et al (2012) found converging evidence for alterations in the lateral occipital lobe, postcentral gyrus, medial temporal lobe, basal ganglia (right caudate and left putamen), and a region in the right hemisphere near the parietal operculum. The authors also suggested that puberty had an impact on the findings reported in VBM studies, namely that brain areas reported as having reduced gray matter in childhood were likely to be reported as having increased gray matter in adulthood, and similarly, brain areas reported as showing increased gray matter in childhood were likely to be reported as having decreased gray matter in adulthood. Thus, discrepancies in VBM findings in ASD may also be related to differences in sample characteristics across studies, particularly age, which impacts developmental trajectories of gray and WM growth (Lenroot et al, 2007).

Importantly, in some cases the nature of the reported volumetric differences (increases, decreases, or no change from neurotypical individuals) seems to be impacted by the age of the cohort under investigation. For example, in the amygdala, Schumann et al (2004) investigated regional volume in a cross-sectional cohort of males with ASD, finding enlarged amygdala volumes in the 8- to 12-year-old group, but no differences from control subjects in the 13- to 18-year-old group. Degree of amygdala enlargement has also been associated with more severe social and communication 
impairment in children aged 3-4 years (Munson et al, 2006) and with anxiety symptoms in children aged 7-14 years (Juranek et al, 2006). Furthermore, in a recent metaanalysis, Stanfield et al (2008) found that amygdala volumes were increased in young children with ASD, but decreased with age, eventually falling to neurotypical volume levels. Even reports of head circumference changes across development, which have been consistently reported in ASD, have tended to suggest an age-specific pattern of initial overgrowth followed by reduced development in ASD (Courchesne et al, 2001).

\section{WM Structure and DTI}

Structural brain imaging studies in autism have increasingly moved from an early focus on gray matter volume to the structure and organization of WM. WM can be measured using MRI in several ways: by measuring the WM volume globally or regionally, the integrity of WM by diffusion tensor imaging (DTI), or the density of specific tracks using tractography, a DTI analytic technique. Atypical WM volume and other measures of WM integrity indicate a structural cause of disruptions in how different brain regions communicate with each other. This research has contributed to an emerging understanding of autism as a disorder of developmental connectivity.

Early studies focused on WM volume in key regions associated with ASD. For instance, regional differences in WM volume have been reported in individuals ranging from toddlerhood to middle age in the cerebellum and in multiple regions of the corpus callosum (eg, Egaas et al, 1995; Hardan et al, 2009; Keary et al, 2009; Piven et al, 1997), a WM tract connecting the left and right hemispheres that is critical for integration of neural information across distant brain regions. Indeed, there is evidence that global brain enlargement in many individuals with autism is due primarily to increased WM but decreased gray matter volume. In one seminal study, Herbert et al (2003) divided the WM in local 'radiate' compartments composed largely of short, locally connecting circuits, and long tracts. They found that in children with ASD there was increased WM volume in more surface cortical regions, while the deep, long pathway structures including the corpus callosum either exhibited lower or unchanged WM volume. The WM differences showing overgrowth in cortical regions are later to myelinate, and suggest a very specific developmental pattern of abnormal WM overgrowth. In contrast, Hardan et al (2009) found that children with ASD had reduced corpus callosum volumes, and that regional reductions in corpus callosum subdivisions were associated with greater reciprocal social interaction impairments, atypical speech, and sensory abnormalities. Together, these brain-based volume differences suggest altered development of brain structures implicated in high-level sociocognitive processes in individuals with ASD.

Diffusion MRI (dMRI; see Box 1; Figure 1) provides a measure of structural connectivity by measuring the

\section{BOX 1}

Diffusion tensor imaging: DTI (Figure I) allows for mapping of WM tracts by measuring the diffusion of water molecules in the brain (eg, Basser and Pierpao 1996). When unrestricted by physical boundaries, water diffuses in an isotropic manner (equally in all directions). In the brain, the diffusion of water is restricted by the physical boundaries of axons and myelin. Thus, in the brain the diffusion of water occurs preferentially along the long axis of the axon. DTI measures the principal direction of water diffusion in each brain voxel and models this information in the shape of an ellipsoid whose long axis points in the direction of the mean axonal direction for the voxel- this information can be reconstructed to identify gross trajectories of WM fiber tracts in the whole brain. The most reported measure in DTI neuroimaging studies is FA, which provides a metric of the degree of diffusion for each voxel and is thought to be a reflection of WM integrity. In DTI, the direction in which fiber tracts travel is typically expressed with different colors that correspond to the primary direction at each point. In addition, various mathematic algorithms can approximate the pathway a particular fiber tract takes as it curves and turns to reach its target, thus isolating fiber bundles throughout the brain. This approach is called tractography. Although DTI has greatly improved our understanding of structural brain connectivity at the macroscale, confounds including the inability to distinguish crossing fibers because of spatial resolution limitations imposed by imaging at the voxel level, the limited ability to quantify connection strengths, and the probabilistic nature of DTI tractography (potentially leading to inaccurate models), remain active areas of methodological development (Craddock et al, 2013)

diffusion of water molecules in the brain to reconstruct WM tracts. The extent to which water molecules diffuse in a consistent direction along the WM tract provides a proxy measure of WM integrity, the most common of which is fractional anisotropy (FA). Diffusion studies in children, adolescents, and adults with ASD have documented multiple structural connectivity differences, mostly suggesting reduced WM integrity in long-range anterior-posterior and interhemispheric fiber tracts (Alexander et al, 2007; BarneaGoraly et al, 2004, 2010; Cheng et al, 2010; Shukla et al, 2011; Sundaram et al, 2008), with few studies reporting heightened WM integrity (Bode et al, 2011; Cheng et al, 2010; Cheung et al, 2009). Notably, many of the specific fiber tracts reported as altered in ASD serve as structural connections between brain regions subserving social cognition. For example, Cheon et al (2011) found reduced connectivity in the right anterior thalamic radiation, corpus callosum, and uncinate fasciculus in children with ASD, suggesting disruption of thalamic-to-frontal structural connectivity. In addition, reduced structural integrity of the corpus callosum has been consistently observed from childhood through adulthood (eg, Alexander et al, 2007; Keller et al, 2007) and may be associated with lower nonverbal IQ in ASD subjects (Alexander et al, 2007). However, observed differences in WM structure may not be causative in ASD, as unaffected siblings also show widespread reductions in structural integrity in medial prefrontal WM regions, anterior forceps, in substructures of the corpus callosum (body and splenium), cingulate, superior longitudinal fasciculous, internal and external capsules, superior temporal gyrus, and temporoparietal junction (Barnea-Goraly et al, 2010). Thus, it is possible that dMRI measures of structural integrity may be indicative of increased risk for ASD diagnosis only.

Despite these findings, a few critical questions remain unanswered in sMRI research among children with ASD. First, how do these structural abnormalities relate to specific 
a

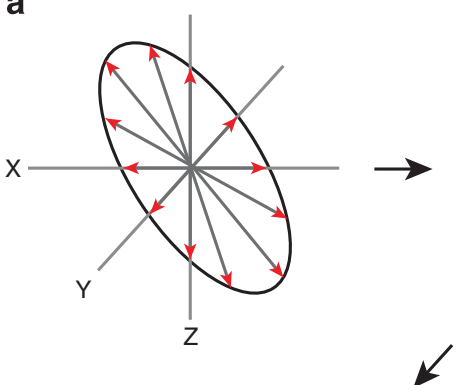

b

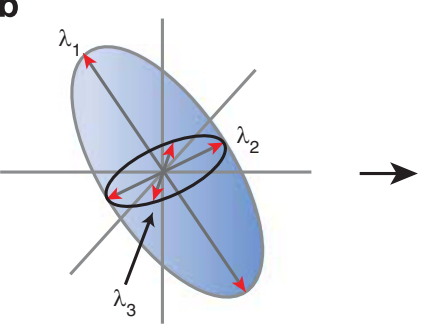

C

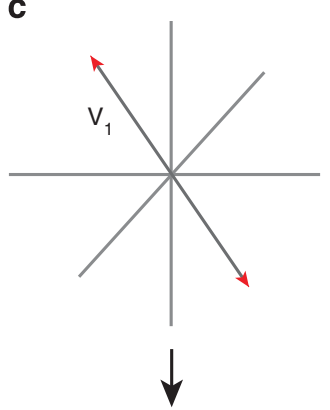

d
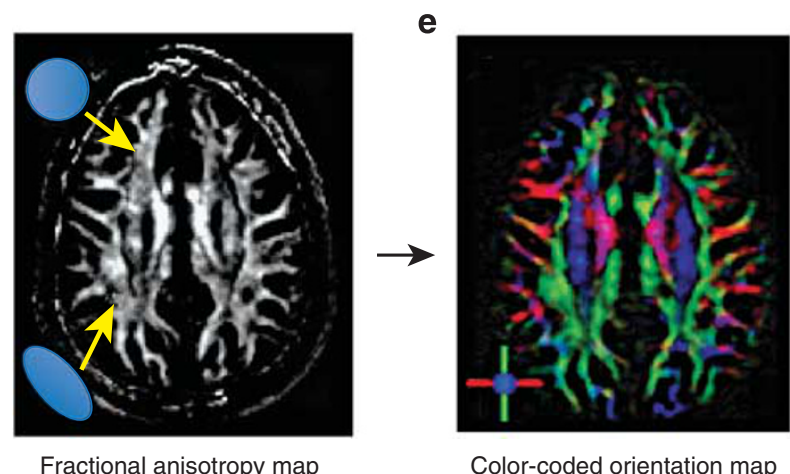
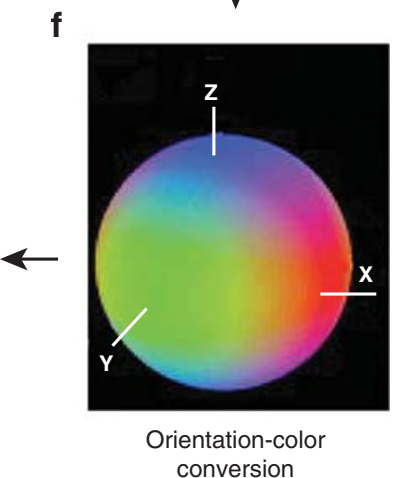

Figure 1. Diffusion tensor imaging. (a) For each voxel, the diffusion of water is measured in multiple directions. (b) The shape of the diffusion ellipsoid is estimated, yielding values for three axes of the ellipse. (c) The primary diffusion direction for a given voxel is taken as the direction of primary fiber orientation. (d) From the diffusion ellipsoid a fractional anisotropy map is created in which isotropic diffusion (spherical-ie, uniform diffusion in all directions) is represented by darker shades, while anisotropic diffusion (directional-ie, with primary diffusion along one axis) is represented by lighter shades. (f) The direction of primary diffusion is color converted and combined with luminosity of the FA map to the yield a color-coded fiber orientation map (e). Reprinted from Mori and Zhang (2006), with permission from Elsevier.

autism symptomatology? Few studies have related variations in brain structural abnormalities to specific phenotypes in autism, other than overall severity. In the language domain, Bigler et al (2007) found that superior temporal gyrus volume related to receptive language ability among typically developing children and adolescents but not those with autism, suggesting a breakdown in the structure-function relationship. In an early study, Pierce and Courchesne (2001) reported that cerebellar hypoplasia in children with ASD was correlated with the severity of repetitive behaviors. Together, these reports lend further support to the notion that heterogeneity in neuroimaging findings may be related to differences in subject characteristics (age, severity of behavioral symptomatology, and so on) across samples, and highlight the need for longitudinal studies of cortical volume development in ASD. However, without comprehensive, large-scale studies that examine multiple regions and multiple phenotypes in the same samples, we cannot yet conclude that specific regional brain volume differences relate to autism phenotypes.

A second major issue concerns whether structural brain abnormalities are causal for ASD features, or whether early behavioral changes and abnormal interactions with the environment shape the development of brain structure to reveal these patterns of group differences. Longitudinal studies can help address this issue. The recent DTI findings of WM abnormalities found in infants at-risk for autism, in an age range that typically precedes diagnosis, suggests that such differences precede and thus may be causal for ASD (Elison et al, 2013; Wolff et al, 2012), although this is not a conclusive evidence. Ongoing studies that combine imaging with intervention may also shed light on causality, however, there are as of yet no published findings of brain changes associated with early intervention.

\section{FUNCTIONAL NEUROIMAGING (fMRI) STUDIES OF CORE ASD DEFICITS}

In contrast to sMRI, fMRI measures neural activity in the brain that relates directly to ongoing cognitive functions in vivo. Numerous fMRI studies in ASD have examined multiple functions including motor, sensory, and language performance, but many studies have converged on the brain's social networks, reflecting an appreciation that autism is primarily a disorder of social cognition (other recent ASD neuroimaging reviews include Dichter 2012; Pelphrey et al, 2011; Verhoeven et al, 2010). It is increasingly accepted that the primate brain has developed a series of brain regions constructed into networks collectively called the 'social brain', evolutionarily developed to recognize and infer the intentions of others (Brothers, 1990). Among the fundamental behaviors associated with social cognition are face recognition, perceiving emotions in others, appreciating the meaning of eye gaze, discriminating biological motion, the ability to infer the mental states of 
others, and responding to social rewards such as smiling. The biological ability of neurons to respond specifically to social stimuli has been demonstrated in studies of nonhuman primates, where single-cell recordings have detected neurons that fire selectively to faces in the superior temporal sulcus (Bruce et al, 1981; Desimone et al, 1984; Perrett et al, 1982), in response to a moving biological entity (eg, a person walking; Bruce et al, 1981), head orientation, or direction of eye gaze in the temporal cortex (Perrett et al, 1985), and when animals perform or watch others perform an action, providing a means of encoding the goals and intentions of others, in the premotor cortex (eg, di Pellegrino et al, 1992; Ferrari et al, 2005; Fogassi et al, 2005). Further, primate studies indicate that social stimuli in themselves are rewarding (eg, Andrews and Rosenblum, 1993, 1994), and that different types of social stimuli provide differential reward value (eg, viewing faces of high-status vs low-status conspecifics; Deaner et al, 2005). Together, these studies suggest that social stimuli and social interactions have an evolutionarily conserved neurobiological underpinning and provide socially relevant stimuli and brain loci with which to test and generate hypotheses about atypical neural function underlying social behavior in ASD. Current diagnostic criteria for ASD include deficits in social communication (eg, non-verbal communication, reciprocity, and so on) and the presence of restricted or repetitive patterns of behavior (eg, restricted interests, atypical sensitivity or interest in sensory stimuli; American Psychiatric Association, 2013), thus we focus our review on task-based fMRI studies tapping into core behavioral deficits observed in individuals with ASD-responding to biological motion, looking at faces, understanding and interpreting the intentions of others (theory of mind (TOM)), language and reward processing, and sensory processing differences.

\section{Face Processing}

Faces convey critical information not only about people's identity, but also about internal states and intentions, as well as about perceptions of the environment (eg, a fearful face in response to a threatening situation). Research in neurotypical infants has shown a preference to attend to the human face over face-like stimuli from very early life (Fantz 1963; Goren et al 1975; Legerstee et al, 1998; Mondloch et al, 1999). Importantly, children with ASD do not show the same attention to faces as neurotypical children. A retrospective study of home videotapes revealed that infants later diagnosed with ASD could be distinguished from neurotypical children based on a lack of attention to other people and faces (Osterling et al, 2002; Osterling and Dawson, 1994), and further, toddlers with ASD appear to be less engaged by faces as they are faster to disengage from faces to attend to a peripheral target (Chawarska et al, 2003, 2010). Reduced attention to social stimuli very early in life may predispose children with ASD to atypical social cognition resulting in altered neurodevelopmental trajectories and ultimately to atypical social behavior (Pelphrey et al, 2011).
Imaging studies suggest that viewing faces is associated with activity in the bilateral fusiform face area (a region of the fusiform gyrus), lateral occipital cortex, posterior superior temporal sulcus (eg, Grill-Spector et al, 2004), and amygdala (especially during fearful face processing; eg, Guyer et al, 2008). It was originally proposed that children, adolescents, and adults with ASD display reduced activation to faces based on fMRI studies finding reduced activity in the fusiform gyrus (Corbett et al, 2009; Critchley et al, 2000; Dalton et al, 2005; Hubl et al, 2003; Kleinhans et al, 2011; Piggot et al, 2004; Schultz et al, 2000; Wang et al, 2004), and amygdala (Corbett et al, 2009; Kleinhans et al, 2011) during face and emotion processing. However, brain activity in these areas may be mediated by extrinsic factors that increase attention. For example, presenting ASD subjects with a cue to direct visual attention to the eye region (ie, a cross hair at eye level before face stimuli presentation; Bookheimer et al, 2008; Davies et al, 2011; Hadjikhani et al, 2004) is associated with increased activity in the fusiform gyrus. Furthermore, in a combined eye-tracking and neuroimaging study, Dalton et al (2005) found that the amount of time spent looking at the eyes was associated with greater activity in the fusiform gyrus and amygdala in individuals with ASD. In addition, Pierce et al $(2004,2008)$ found that when participants with ASD viewed faces of personally significant individuals (ie, mother, friend), activity in the fusiform gyrus was comparable to that of controls. Together, these studies suggest that the original findings of hypoactive responses to faces in ASD are due to either avoidance of or lack of attention to the eye area. It appears that 'normative' levels of activity in the fusiform gyrus may be elicited from ASD subjects by explicitly cueing attention to face stimuli, but doing so may also increase anxiety responses; indeed increased anxiety with direct gaze may underlie eye contact avoidance in ASD (Kleinhans et al, 2010).

\section{Biological Motion}

The ability to detect salient social stimuli depends critically on the ability to detect biological motion, a behavior present in infancy (Hoehl et al, 2009; Simion et al, 2008). Examples of biological motion include following eye gaze or discerning the patterns of how people walk and move, as opposed to mechanical motion. This skill develops quickly in early infancy, as neurotypical children can detect eye gaze deviations during social interactions at five months of age (Symons et al, 1998). Early attention to biological motion likely heightens the amount of exposure infants receive to social stimuli, setting the stage for ongoing cognitive development in neural substrates involved in social and emotional cognition. Importantly, 2-year-old children with autism show an early behavioral deficit in attention to human biological motion visualized in point-light animations (Klin et al, 2009), an impairment that persists into late childhood (Blake et al, 2003).

Neuroimaging investigations of biological motion have used a variety of stimuli including animated human 
characters moving their mouth, hand, or eyes (Morris et al, 2008; Pelphrey et al, 2005; Pelphrey and Morris, 2006), moving elements designed to display a range of human-like qualities (eg, a human, a robot, a grandfather clock, and a mechanical assembly; Carter and Pelphrey, 2006), and point-light displays of both non-biological (eg, a spinning wheel) and biological (eg, walking) motion (Herrington et al, 2011). These studies suggest that in neurotypical individuals, processing biological motion relies on neural activity in the superior temporal sulcus, (Carter and Pelphrey, 2006; Morris et al, 2008; Pelphrey et al, 2005; Pelphrey and Morris, 2006), inferior frontal gyrus, amygdala, and visual areas including the fusiform gyrus (eg, Herrington et al, 2011). In individuals with ASD, perception of biological motion is consistently associated with reduced activity in the superior temporal sulcus compared with controls when viewing point-light displays (Freitag et al, 2008; Herrington et al, 2007; Koldewyn et al, 2011). Individuals with ASD also show hypoactivation of the ventrolateral prefrontal cortex (Davies et al, 2011), temporo-parietal junction and superior temporal sulcus (von dem Hagen et al, 2013) when viewing direct $v s$ averted gaze. Reduced activity in neurotypical correlates of biological motion in individuals with ASD suggests atypical processing of biological motion cues present in everyday social contexts. In neurotypical individuals, detection of biological motion may serve to direct attention to socially relevant stimuli, a behavior that appears to be impaired in ASD.

\section{TOM and Pragmatic Language}

Theory of mind (TOM) is described as the ability to understand and infer the actions and intentions of others (BaronCohen, 1991; Frith and Frith, 1999). It is well documented that individuals with ASD show deficits in higher-level social information processing, such as recognizing social faux pas (Baron-Cohen et al, 1999), and extrapolating the mental state of others based on cues expressed through the eyes and by voice (Baron-Cohen et al, 1997, 2001; BaronCohen and Hammer, 1997). In neurotypical individuals, TOM skills such as reasoning about the beliefs of others or their state of mind (eg, Saxe et al, 2009; Saxe and Kanwisher 2003) elicit neural activity in the superior temporal sulcus, temporo-parietal junction, medial prefrontal cortex (MPFC), and temporal poles (Gallagher et al, 2000; Saxe et al, 2009; Saxe and Kanwisher, 2003). In ASD, neuroimaging studies of TOM have shown reduced activity in the left inferior frontal gyrus (Harris et al, 2006; Just et al, 2004), MPFC (Castelli et al, 2002; Kana et al, 2009, 2014; Nieminen-von Wendt et al, 2003; Wang et al, 2007), and temporo-parietal junction (Kana et al, 2014). Notably, many of these regions overlap with those activated in biological motion, suggesting a potential common network underlying a range of social deficits in ASD.

Paralleling the deficits seen in TOM abilities, individuals with ASD also show deficits in language processing, particularly high-level language processing such as the proper use and comprehension of pragmatics, or appropriate use of language in a social context (Boucher, 2003; for a review, see Groen et al, 2008). Behavioral studies have reported atypical production and comprehension of prosody (the rhythm, stress, or intonation of speech) in children with highfunctioning ASD (eg, McCann et al, 2007). Deficits in prosodic comprehension have been documented in both children and adults with ASD, who have difficulty inferring the mental state of others when relying on vocal intonation cues (eg, Golan et al, 2007; Peppé et al, 2007; Rutherford et al, 2002). In line with the behavioral deficits observed in ASD, functional neuroimaging studies also report atypical activation of language relevant brain areas. For example, a growing number of fMRI studies have reported more bilateral or right-lateralized activity in adults (Kleinhans, et al, 2008a; Mason et al, 2008; Tesink et al, 2009) and children (Knaus et al, 2010; Redcay and Courchesne, 2008) with ASD. Although some studies have shown hyperactivation (Wang et al, 2006), others have reported hypoactivation (Gaffrey et al, 2007; Wang et al, 2007), and a few others have reported simultaneous decreased activity in frontal brain regions and increased activity in posterior temporal areas (Harris et al, 2006; Just et al, 2004) during basic language processing.

A handful of studies have focused on higher-level language abilities in ASD by assessing the neural correlates of pragmatic or prosodic cues in language comprehension. In one study of pragmatic language, Tesink et al (2009) examined neural activity during a task in which adults with ASD made inferences about a speaker's characteristics (ie, gender, age, and social background) using voice-based cues. Although both ASD and neurotypical controls showed equivalent behavioral performance, the ASD group showed greater activity in the right inferior frontal gyrus, suggesting an atypical and potentially compensatory neural mechanism in individuals with ASD. A second study of pragmatic language processing found that adults with ASD showed increased activity in the left supramarignal gyrus compared with controls (Hesling et al, 2010). Several other investigations have focused on the neural correlates of prosodic cues in ASD by examining brain activity during processing of ironic $v s$ sincere speech. Wang et al (2006) used a task in which children and adolescents with ASD listened to short scenarios and made a choice to indicate whether the speaker was sincere or sarcastic. Although both the ASD and neurotypical control groups performed well on the task, the children with ASD showed increased activity in the right inferior frontal gyrus and bilateral temporal pole, suggesting more effortful processing in the ASD group during high-level prosodic language processing. A second study by Wang et al (2007) tested whether explicit instructions to attend to facial or tone of voice cues could regulate neural activity in children with ASD during ironic speech processing. Indeed, the authors demonstrated that while the ASD group showed reduced activity in the MPFC during ironic vs sincere speech (a region associated with TOM), this activity was modulated by specific instructions to attend to face or voice 
cues, and that activity in this region was negatively correlated with social impairment in ASD (ie, less activity in the MPFC was associated with greater social impairment). Finally, a recent study by Colich et al (2012) showed that when processing ironic $v s$ sincere speech, children with ASD show a more bilateral pattern of activation in right hemisphere language homologues, and in brain areas implicated in TOM processing (such as the MPFC) compared with neurotypical children. Together, these studies suggest that compensatory activity in distributed brain regions in individuals with ASD may allow for normal behavioral performance during high-level language processing, and that atypical neural activity may be modulated by attention to secondary social (ie, face and voice) cues. Further, although language deficits are a common feature of ASD, it is no longer required for an ASD diagnosis (DSM V); thus heterogeneity in the ASD phenotype may help explain the range of findings in language regions among children with ASD.

\section{Reward Processing}

In humans, social cues such as smiles are processed early in infancy and appear to be highly rewarding, biasing attention toward these cues. Early attentional biases to social stimuli may be modulated by increased neural mediated rewardvalue for these stimuli. Evolutionarily, successful social interaction in infancy is critical for survival as it impacts mother-offspring bonding (Lévy et al, 1995). One general theory of autism posits that reduced social motivation underlies the development of autism (Chevallier et al, 2012); reduced reward responsiveness could provide a potential neural basis of reduced social motivation. Animal studies suggest that reward processing involves activity in the anterior cingulate cortex, orbitofrontal cortex, and ventral striatum (Febo et al, 2005; Young et al, 2005). Importantly, recent neuroimaging studies have found that the same areas underlie reward processing in humans, including food rewards (O'Doherty et al, 2002), monetary rewards (O'Doherty et al, 2001; Thut et al, 1997), and social rewards such as viewing happy faces (Phillips et al, 1998).

Given that children with ASD display reduced attentional biases to social stimuli, recent neuroimaging work has begun to investigate whether decreased activity in socialreward brain regions may have a role in atypical ASD social behavioral and neural phenotypes. These studies have primarily contrasted social reward stimuli (ie, faces) to monetary reward in individuals with ASD and neurotypical controls. Compared with controls, children, adolescents, and adults with ASD show aberrant activity during monetary reward conditions in the anterior cingulate, frontal cortex, and ventral striatum (Dichter et al, 2012; Kohls et al, 2013; Schmitz et al, 2008; Scott-Van Zeeland et al, 2010). During positive social reward conditions (ie, smiling faces), ASD participants show reduced striatal activity in comparison with controls (Delmonte et al, 2012; Scott-Van Zeeland et al, 2010). Recently, Cascio et al (2014) investigated brain activity in children with ASD during exposure to images of participant-specific restricted interest objects, aiming to disentangle whether the observed difference in neural activity during reward processing in ASD may be modulated by the salience of the reward, or instead represent broad functional atypicalities. Although both controls and individuals with ASD showed activity in reward-related circuitry when viewing pictures of their own interests, only the neurotypical group showed similar activity when seeing pictures of another child's interest. Conversely, the ASD group showed reduced activity in reward-related areas including the insula and anterior cingulate cortex when seeing pictures of another child's interest. Thus, similar to results in neuroimaging studies of face processing, extrinsic factors that increase attention to personally relevant rewarding stimuli may be associated with more neurotypical activity in individuals with ASD. As narrow, selective interests are a core feature of children with ASD, reduced neural responses in reward-related brain regions to nonpreferred stimuli has face validity; however, these data do not provide a mechanistic causative explanation for these atypical fMRI findings.

\section{Sensory Over-Responsivity}

Many children with ASD display over-responsivity to sensory stimuli (eg, scratchy clothing and vacuum cleaners), but others are under-responsive and many are both overand under-responsive depending on the situation (eg, Liss et al, 2006). Sensory processing issues in individuals with ASD have been challenging to study. Physiological studies often fail to find group (ASD vs control) differences, likely because they fail to take into account within-ASD heterogeneity (Rogers and Ozonoff, 2005). A recent neuroimaging study of sensory over-responsivity (SOR) found that children with ASD display hyper-reactivity in limbic areas (amygdala and hippocampus) and primary sensory cortices to mildly aversive visual and auditory sensory stimuli (Green et al, 2013). Notably, this study took into account individual levels of SOR, and found that activation in these areas was related to parent-reported SOR in both groups of children. Cascio et al (2012) compared neural response with pleasant, neutral, and unpleasant tactile stimuli in adults with and without ASD. They found that in general, the ASD group was under-responsive to the stimuli compared with the TD group, with the TD group having greater activation in multiple brain areas including the primary somatosensory cortex, middle frontal gyrus, superior temporal gyrus, and cingulate cortex. However, the ASD group had greater activation in the thalamus (pulvinar) in response to both the pleasant and unpleasant stimuli, and in the posterior cingulate and insula in response to the unpleasant stimulus. Greater insula response was correlated with severity of ASD symptoms. The authors hypothesized that individuals with ASD are hyporesponsive to pleasant tactile stimuli in primary and association somatosensory areas, but are hyperresponsive to unpleasant stimuli in areas associated 
with emotional processing of sensory stimuli. Voos et al (2013) also found that in neurotypical adults, higher levels of autism traits were associated with diminished response to pleasant touch in the superior temporal sulcus and orbital frontal cortex. Although neither the Cascio et al (2012) nor Voos et al (2013) study examined individual differences in sensory processing, these studies suggest that social touch is processed differently from unpleasant sensory stimuli in individuals with ASD.

In summary, a broad range of fMRI studies tapping into several aspects of social cognition and other core deficits show abnormal brain activity in ASD. A recent metaanalysis of 39 task-based fMRI studies in children and adults with ASD found that during social neuroimaging experiments, individuals with ASD had reduced probability of activation in the anterior cingulate cortex, right amygdala, and left frontal gyrus, as well as greater probability of activation in somatosensory brain regions (Di Martino et al, 2009). In particular, research shows reduced engagement throughout brain networks involved in processing social stimuli and responding to both positive and negative affect, as well as brain systems involved in understanding the emotional states of others (eg, Dapretto et al, 2006) and regulating sensory and emotional experience. Interestingly, in some cases there is increased activity in regions not typically associated with task performance, which may suggest engagement of compensatory neural systems. Of note, many regions showing reduced activity under certain conditions can show more normative responses when attention is explicitly directed to the task at hand, when the salience of the stimuli is increased, or when stimuli or tasks are more personally relevant to the individual. This argues in favor of the social motivation hypothesis of ASD, whereby a lack of intrinsic motivation to attend to social stimuli early in life leads to an altered developmental trajectory of neurocognitive development in ASD.

\section{STUDIES OF BRAIN CONNECTIVITY IN ASD}

Although functional neuroimaging studies have informed our understanding of the regional neurobiological underpinnings of ASD during social-emotional cognition, recent work has focused on elucidating differences at the network/ systems level. Another way to conceptualize functional brain abnormalities in autism is to look at activity not within individual brain regions, but at the way in which regions within social brain networks connect with each other, working in concert to perform complex tasks. It has been hypothesized that very early disruption in both the structural architecture and functional connectivity of local circuits in individuals with ASD may impact maturation of large-scale brain networks required for complex cognitive processing (Belmonte et al, 2004; Courchesne and Pierce 2005; Geschwind and Levitt 2007; Just et al, 2004; Mundy et al, 2009). These structural and functional abnormalities may thus prevent typical experience-dependent reorganization of neural circuitry into fully integrated networks, which are critical for understanding and initiating complex social behavior.

\section{Connectivity in Task-Related Brain Networks}

In ASD, task-based functional connectivity (fcMRI; Figure 2) studies have shown altered connectivity in multiple brain networks underlying complex social and emotional information processing. In an early study, Just et al (2004) found that during a sentence comprehension task, individuals with ASD displayed reduced connectivity between multiple highlevel association cortical areas. These findings led the authors to suggest that cognitive deficits in ASD may be due to a general underconnectivity of brain regions important for information integration. In support of this hypothesis, many other task-based connectivity studies have reported underconnectivity in individuals with ASD in taskrelated brain areas including fronto-parietal connections during tasks involving working memory (Koshino et al, 2005), visuomotor coordination (Villalobos et al, 2005), visual imagery (Kana et al, 2006), executive functioning (Just $e t a l$, 2007), response inhibition (Kana et al, 2007), facial processing (Kleinhans et al, 2008b; Rudie et al, 2012b), theory of mind (Kana et al, 2009), and during rest (Kennedy and Courchesne, 2008b). However, others have reported overconnectivity of neural networks in ASD, (eg, Mizuno et al, 2006; Noonan et al, 2009; Rudie et al, 2012b; Shih et al, 2010; Turner et al, 2006).

Importantly, recent functional and structural neuroimaging studies have demonstrated that altered brain connectivity is related to behavioral phenotypes in ASD. In a recent study, Abrams et al (2013) investigated resting state functional connectivity of the bilateral posterior superior temporal sulcus in children with ASD. The posterior superior temporal sulcus is involved in human voice processing in neurotypical individuals (Belin et al, 2000), but fails to activate in individuals with ASD (Gervais et al, 2004). Children with ASD showed reduced connectivity between the posterior superior temporal sulcus and many reward-related brain regions including the nucleus accumbens, insula, orbitofrontal cortex, and ventromedial prefrontal cortex. Importantly, the authors found that reduced connectivity between the posterior superior temporal sulcus and reward circuitry was associated with greater communication deficits. These findings suggest that the human voice may be less intrinsically rewarding for children with ASD and as a consequence negatively impact language outcomes.

\section{Resting State Connectivity fMRI}

One major limitation of task-based functional MRI studies is that they require subject participation and thus are typically limited to older, higher functioning children with autism. Brain changes in later years may be a consequence rather 

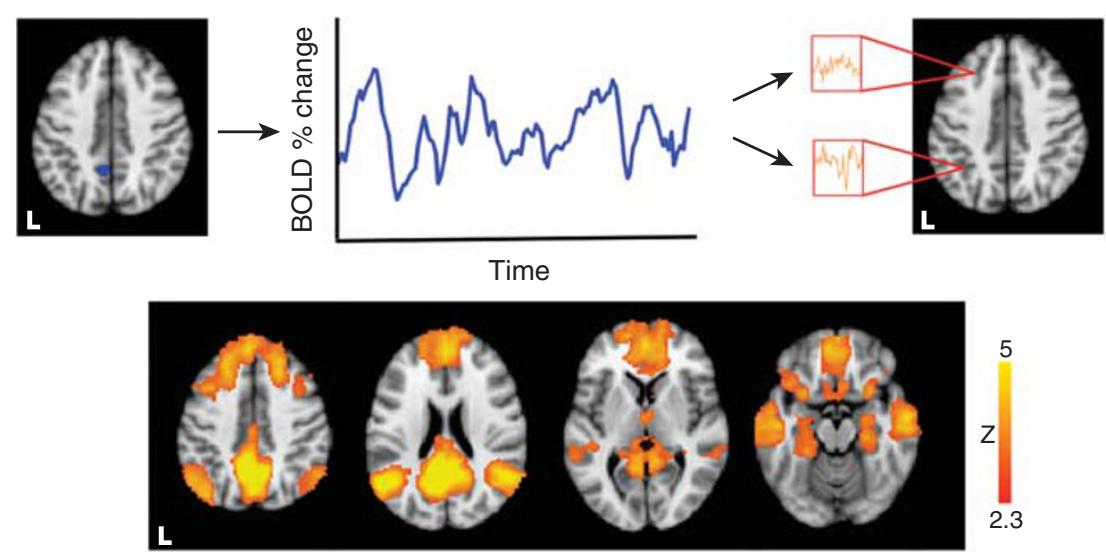

Figure 2. Seed-based functional connectivity. The average BOLD signal time series is extracted from a seed region (eg, the precuneous). The time series of activity from this seed region is then correlated with the time series of activity of all other voxels in the brain, yielding maps of coactivating brain areas. Brain areas represented in these maps are inferred to be part of the same functional brain network, as activity in these regions is highly correlated with one another.

\section{BOX 2}

Resting state connectivity: resting state-functional connectivity MRI (rs-fcMRI) refer to a growing body of literature in which imaging is performed in the absence of an overt task to detect brain regions where the BOLD fMRI signal is co-fluctuating; these methods provide a map of intrinsic functional brain networks. There are two main methodological approaches used to identify resting state brain networks. (I) Seed-based methods (Figure 2), in which the average BOLD time course is extracted from a seed region and correlated with every other voxel in the brain, thereby identifying voxels with BOLD signal time series co-fluctuating with that of the seed. (2) Independent component analysis (ICA), in which statistically

independent components of the resting state BOLD scan are identified in a datadriven manner, providing the user with all statistically independent time-varying signals within the data. Although a main advantage of ICA is that it provides an unbiased metric of all components in the data (ie, no a priori hypotheses related to a seed region of interest are needed), a critical disadvantage is that individual users must decide which components are biologically meaningful (eg, as opposed to noise components) and merit reporting and further investigation. Some of the most common resting state brain networks include, sensory networks such as visua and auditory systems, attentional networks that include regions such as dorsal prefrontal cortex, the default mode network, which is negatively correlated with task performance, and the salience network, which relates to identifying relevant information in one's environment. Critically, these networks persist both during task-based activity and when individuals are at rest, as well as during sleep and sedation. Connectivity-based methods are uniquely suited to inform our understanding of network-level brain activation, providing insight into the history of coactivation between brain regions, and atypicalities indicative of clinical diagnoses However, interpretation of fcMRI results can be difficult because connectivity measures can be impacted by differences in underlying brain structure, cognitive state, and subject motion during data acquisition (Buckner et al, 2013).

than a cause of abnormal social development, and findings may not generalize to lower-functioning or non-verbal children or those with more severe social deficits. Furthermore, traditional fMRI studies comparing neural functioning between ASD and neurotypical populations must control for baseline differences in task performance, and ensure that the task is well designed to address specific questions relating to ASD neurobiology. A relatively new approach that alleviates many of these concerns aims to understand functional brain connectivity by examining the interactions between brain regions not during task performance but while subjects are at rest. Resting state-functional connectivity MRI (rs-fcMRI; see Box 2) is a method in which fMRI is performed in the absence of an overt task in order to detect low-frequency
$(<0.1 \mathrm{~Hz})$ fluctuations in neural activity and identify coactivating brain regions (ie, intrinsic functional brain networks) (Biswal et al, 1995; for a review, see Fox and Raichle 2007). Findings of synchronized activity across brain regions, both at rest and during task conditions, suggest that functional brain organization consists of multiple interacting large-scale neural networks (eg, Calhoun et al, 2008; Smith et al, 2009). Neuroimaging studies of ASD have recently begun to characterize functional connections within and between brain networks.

In neurotypical individuals, rs-fcMRI studies have identified multiple, widely replicated brain networks (for a review of resting state networks present in early development, see Hoff et al, 2013, and van den Heuvel and Hulshoff Pol, 2010 for a review of findings in adults). Here we will focus on networks implicated in ASD etiology. Perhaps the most widely studied functional connectivity network important for social cognition is the so-called 'default mode network' (DMN), which comprises the posterior cingulate cortex (PCC), MPFC, lateral temporal cortex, inferior parietal lobule, and hippocampal formation (Buckner et al, 2008). The DMN has been shown to be involved in internally directed cognition, as it is deactivated during goal-directed behaviors and shows an anticorrelated relationship with the 'attentional control network' (Stevens et al, 2009). In children, adolescents, and adults with ASD, reports consistently suggest that connectivity between nodes of the DMN is diminished (Assaf et al, 2010; Cherkassky et al, 2006; Kennedy and Courchesne, 2008a,b; Monk et al, 2009; Rudie et al, 2012a; Weng et al, 2010). This is consistent with the known role of specific DMN nodes in tasks of social cognition (eg, watching social interactions; Iacoboni et al, 2004) and the observed behavioral deficits characteristic of ASD (ie, atypical TOM processing and social interactions). However, the DMN interacts in a dynamic manner with other brain systems and is unlikely to be the only functional network affected in ASD.

Another network that has recently received a substantial amount of attention in the ASD literature is the 'salience 
network' (Seeley et al, 2007), which is involved in identification of the most relevant information in one's environment, including social stimuli. Primary nodes of the salience network are the anterior cingulate cortex and anterior insula, which neuroimaging studies suggest have a role in perception of social exclusion (Bolling et al, 2011; Masten et al, 2011) and cognitive control (Agam et al, 2010). A recent study (Uddin et al, 2013) compared connectivity in large-scale brain networks in children with ASD and matched controls. Hyperconnectivity was observed in a number of brain networks, including the DMN and the salience network. Importantly, salience network connectivity values showed the highest classification accuracy (CA) in parsing neurotypical from ASD individuals, and correlated with severity scores for restricted interests and repetitive behaviors. Another study investigating connectivity of the salience network in adolescents and adults found reduced connections with the medial temporal lobe network, including the amygdala (von dem Hagen et al, 2013). Reduced functional connectivity between networks may suggest altered integration of social-emotional information across distributed brain regions in individuals with ASD.

Further evidence for network-level dysfunction in ASD comes from two recent studies by Keown et al (2013) and Supekar et al (2013), which found increased functional connectivity across multiple brain networks in children with ASD. Both studies also found that increased connectivity was associated with greater severity of ASD impairments. As both under- and over-connectivity have been reported in ASD, a major challenge facing the autism neuroimaging field is to reconcile these seemingly discrepant findings. Findings of hyper- $v$ s hypo-connectivity in ASD may depend on the nature of the task-related demands, the specific brain networks under investigation, studyspecific methodological choices, as well the age of the cohort under investigation (Rudie and Dapretto, 2013). For example, Uddin et al's (2013) review of the functional connectivity literature in ASD suggests that studies of adults and adolescents with ASD tend to report hypo-connectivity compared with neurotypical controls, whereas studies of younger children often report hyper-connectivity-indicating that differences in sample characteristics can lead to opposite findings. Taken together, these studies highlight the complexity of brain network organization in ASD and the need for longitudinal investigations in order to elucidate the entire developmental trajectory of altered connectivity in ASD.

\section{Graph Theoretical Methods}

As described above, many neuroimaging studies report differences in regional network connectivity in ASD; however, how these findings may be reflective of more complex systems-level dysfunctions across the brain in individuals with ASD remains unclear. Recently, researchers have begun using graph theory methods to address this question by modeling the brain as a network of integrated and segregated systems composed of hundreds of brain regions or 'nodes'. Graph theoretical approaches depict the brain as a hierarchically organized network comprising large-scale functional systems or modules (for a review, see Wang et al, 2010). Each module is made up of discrete brain regions (nodes) and the connections between these nodes (edges). In the brain, functional and structural networks are 'small-world' in nature, meaning that they are efficient at both a local-systems and global-systems level (Watts and Strogatz, 1998). Graph theory measures such as the number of nodes, edges, and small-world characteristics such as modularity can be quantified (Bullmore and Sporns, 2009; Rubinov and Sporns, 2010) and compared across populations during development (eg, Fair et al, 2009; Hagmann et al, 2010), and in diseases such as schizophrenia (eg, Bassett et al, 2008) and Alzheimer's disease (eg, Supekar et al, 2008). Graph theoretical metrics are useful in that they go beyond simple connectivity analyses to describe large-scale properties of how brain networks are organized and how they interact.

To date, there have been relatively few graph theory studies of ASD, and reported findings have been mixed. In a whole-brain investigation of network properties across four functional brain networks, Redcay et al (2013) found few differences between adolescents with ASD and neurotypical controls, except for greater 'betweenness centrality' (a measure of how often the shortest path goes through a given node, or its centrality to the network) in a parietal region of the DMN in individuals with ASD. In another study of adolescents with ASD, Keown et al (2013) found increased local functional connectivity in temporo-occipital regions, which was associated with greater scores of ASD symptom severity. In a third study of children and adolescents with ASD, Rudie et al (2013) investigated both functional and structural connectivity using graph theory methods, finding alterations in local and global network measures including modularity and local efficiency of brain networks in children with ASD. Overall, graph theory studies of ASD suggest wide-scale disruptions in how brain networks communicate, suggesting that in autism, critical networks are less modular and less segregated from one another, with abnormalities both within and between networks. Although graph theoretical approaches are in their infancy, further research may elucidate more complex interactions between large-scale brain networks in ASD.

\section{Integrating Imaging and Genetics}

The identification of genetic contributions to ASD has progressed rapidly in the last decade (for a review, see Huguet et al, 2013 and Persico and Napolioni, 2013). Mirroring the heterogeneity observed in behavioral phenotypes, hundreds of genes have been implicated in conferring increased risk for ASD. Importantly, the biological functions of many ASD-associated genes impact the formation of neural circuits in the developing brain (Won et al, 2013), including prenatal transcription regulation and synapse development, and are enriched in outer cortical layers of the brain (Parikshak et al, 2013). However, little is known about how 
autism risk genes relate to brain structure, function, and behavior. For over a decade, research on a range of common genetic variants related to neurobehavioral disorders has demonstrated differences in brain structure and function in risk gene carriers despite having no overt behavioral symptomatology (for a review, see Hariri and Weinberger 2003). The field of imaging-genetics examines the relationship between risk genes and brain structure and function, conceptualizing neuroimaging metrics as potential endophenotypes. As MRI metrics of brain functional and structural connectivity are both heritable (Chiang et al, 2011; Fornito et al, 2011; Glahn et al, 2010; Kochunov et al, 2010; Koten et al, 2009) and altered in individuals with ASD, neuroimaging endophenotypes are well suited to inform our understanding of how genetic risk impacts brain circuitry. A key goal of imaging-genetics research is to elucidate neural mechanisms by which genetic heterogeneity may give rise to phenotypic heterogeneity in ASD (Figure 3). As genetics research suggests that many common single-nucleotide polymorphisms are related to increased risk for autism diagnosis (for a review, see Klei et al, 2012), imaging studies have investigated whether stratifying neuroimaging data by common genetic risk factors can inform understanding of ASD neurobiology.

To date, neuroimaging-genetics studies have taken two forms: studies of the effects of ASD-associated risk alleles on brain measures in neurotypical children, adolescents, and adults (eg, Clemm von Hohenberg et al, 2013; Dennis et al,
1. Heterogenity of Neuroimaging phenotypes

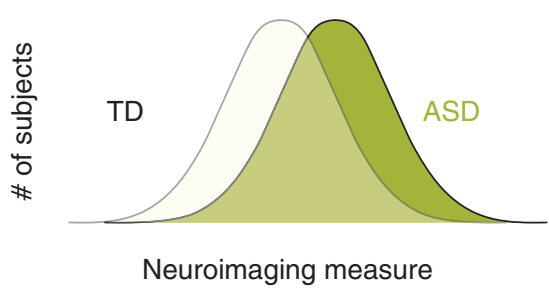

2. Stratify Neuroimaging Phenotype (diagnosis independent)

3. Stratify using Risk Variant(s) that modulate phenotypes across human populations

4. Reduce heterogeneity using genotype and diagnosis

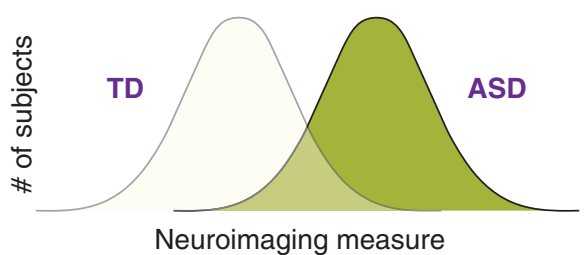

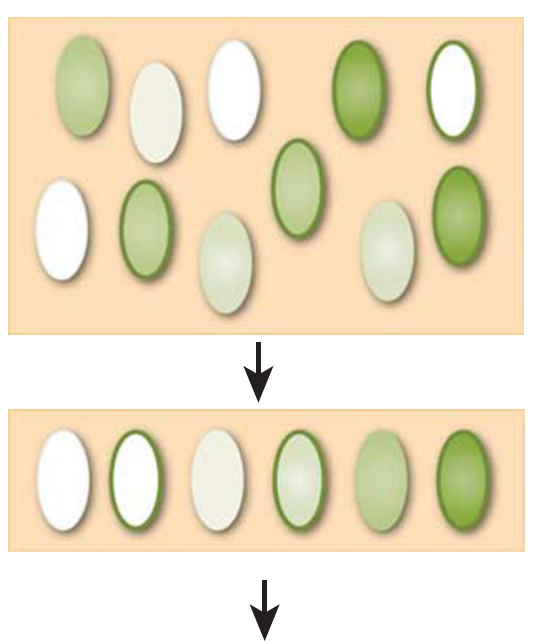

SNP - common (>5\%) functional risk variant
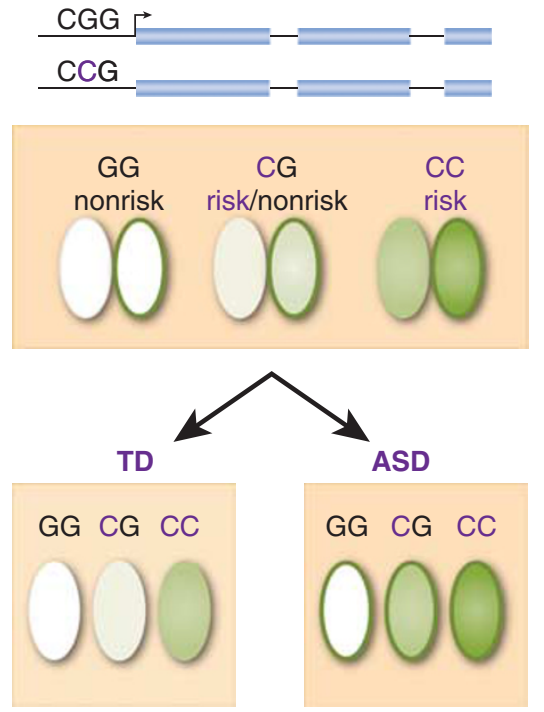

Figure 3. Parsing phenotypic heterogeneity using imaging-genetics. (1) A sample population contains subjects who display a range of ASD-associated neurocognitive phenotypes (shades of green within ovals) and a subset of individuals with a diagnosis of ASD (dark green border outlining ovals). (2) When subjects are stratified by neuroimaging phenotypes, a continuous range of phenotypes is observed across neurotypical subjects and those with ASD. (3) Subjects' neuroimaging data may also be stratified by common genetic risk variants (ie, those that occur in $>5 \%$ of the population) for a particular neurobiological disorder. (4) Combining these data allow for added stratification of phenotypic heterogeneity by creating subgroups of neurotypical and affected individuals, ultimately elucidating neural mechanisms unique to the diagnosis of ASD vs risk variant status. Reprinted from Rudie et al (2012a), with permission from Elsevier. 
2011; Hedrick et al, 2012; Raznahan et al, 2012; Sauer et al, 2012; Tan et al, 2010; Voineskos et al, 2011; Whalley et al, 2011) and studies comparing the effects of ASD-associated risk alleles on children and adolescents with ASD compared with neurotypical controls (eg, Rudie et al, 2012a; Scott-Van Zeeland et al, 2010). Scott-Van Zeeland et al (2010) investigated the impact of the contactin-associated protein-like 2 (CNTNAP2) rs2710102, C risk allele on functional connectivity in children and adolescents with ASD. Results suggested that while nonrisk allele carriers (in both neurotypical and ASD groups) displayed connectivity between frontal cortex and language regions in the left hemisphere, risk allele carriers showed a pattern of diffusely increased functional connectivity with frontal cortex and temporal regions. A second study by Rudie et al (2012a) found that children and adolescents carrying the met receptor tyrosine kinase (MET) rs1858830, C risk allele had decreased functional connectivity between the PCC and MPFC and reduced WM integrity in the splenium of the corpus callosum, cortical spinal tract, and inferior longitudinal fasciculus. Interestingly, the authors also identified a significant interaction whereby the presence of one or two risk alleles in ASD children had a significantly larger impact on functional connectivity values than in neurotypical children.

Together, these results suggest that these and other ASD liability genes may confer risk through their effects of brain function and structure in regions involved in social and emotional cognition. Although not causal, autism risk genes may bias the brain toward patterns of neural activity and connectivity that are atypical, and in combination with a range of additional genetic and environmental factors may contribute to abnormal brain development that ultimately underlies ASD symptoms. Future neuroimaging studies should continue to use relevant genetics data to help explain variance observed in both behavioral and brain-based phenotypes of ASD, as well as to improve diagnostic tools and treatment strategies for individuals falling throughout the autism spectrum (Fox and Greicius 2010).

\section{Machine Learning}

Prediction and classification of diagnostic status based on neuroimaging data represents a powerful tool for improved clinical care in ASD. Machine learning algorithms extract highly relevant components from neuroimaging data to classify an individual's diagnostic status (see Box 3; Figure 4). Machine learning algorithms have been applied to neuroimaging data to identify ASD from neurotypical subjects using MRI measures of gray and WM volume (CA $81 \%$ and $68 \%$, respectively, Ecker et al, 2010), regional cortical thickness (CA 70-87\%; Jiao et al, 2010; Zhou et al, 2014), VBM (CA 79-92\%; Uddin et al, 2011), DTI (CA 80\%; Ingalhalikar et al, 2011), and resting state functional connectivity (CA 71-89\%; Anderson et al, 2011; Uddin et al, 2013). Variations in CA may be attributed to the types of classification systems used, which MRI-based metrics are utilized, and the number of features on which classification is determined
$\mathrm{BO} \times 3$

Machine learning. Traditional machine learning methods (Figure 4; also see Klöppe et al, 2012) begin by feeding neuroimaging data from labeled cases and controls (the training data set) into a mathematical classifier and identifying relevant components (or features) from the neuroimaging data that contribute to group discrimination. The classifier then uses the training data set to establish a set of rules that allow for optimal discrimination of patient and control groups, converging on an optimal classification algorithm. Finally, this algorithm is applied to a new set of neuroimaging data consisting of non-labeled cases and controls and classification accuracy (CA) is assessed by calculating the number of correct positive (eg, ASD) and negative (eg, neurotypical) classifications for the new data. A major advantage of this approach is that it allows individual subjects to be evaluated for likelihood of ASD diagnosis. An important limitation to the application of this method to the study of autism is the inherent heterogeneity of the ASD subject population, which can decrease overall CA. There is great potential to overcome this limitation by studying circumscribed ASD subgroups (including restrictions based on age, comorbid symptoms, and so on) and collection of larger data sets.

(eg, number of brain areas included in measures of regional cortical thickness). In a recent study, Nielsen et al (2013) used machine learning to evaluate whole-brain resting state fMRI data collected from 16 sites in 964 subjects ranging in age from 7 to 64 years from the Autism Brain Imaging Data Exchange (ABIDE). The maximum $\mathrm{CA}$ achieved by this study was just $60 \%$, much lower than CAs reported for single site studies. However, the authors note that higher CAs were calculated for sites where longer resting state scans were collected, providing support for longer fMRI imaging times in future machine learning paradigms.

Very recently, machine learning algorithms have been applied to address questions of heterogeneity in ASDaiming to distinguish between ASD sub-populations. Sato et al (2013) used inter-regional whole-brain cortical thickness correlations and machine learning to predict scores on the Autism Diagnostic Observation Scale (Lord et al, 1989) in children, adolescents, and adults with ASD, yielding a significant correlation $(r=0.362)$ between predicted and actual values. In another study, Uddin et al (2013) classified children with and without ASD using large-scale brain network connectivity measures. Connectivity of the salience network was best able to classify subjects, achieving a CA of $83 \%$, with BOLD signal in this network also predicting restricted and repetitive behaviors in the sample of children with ASD. Although the machine learning literature in ASD is just beginning to emerge, these studies suggest that neuroimaging data evaluated with machine learning may help to identify brainbased biomarkers that correlate with severity of ASD symptomatology. Continued methodological development of this technique will undoubtedly further our understanding of neural signatures of ASD sub-populations.

\section{METHODOLOGICAL CONSIDERATIONS}

Despite the growing corpus of brain imaging studies in ASD, many discrepant findings make it difficult to draw broad and definitive conclusions about brain connectivity abnormalities in ASD. As described in detail by Rudie and Dapretto (2013), there are a few major methodological considerations that may help to explain the seemingly discrepant findings between many prior studies of neural 
a
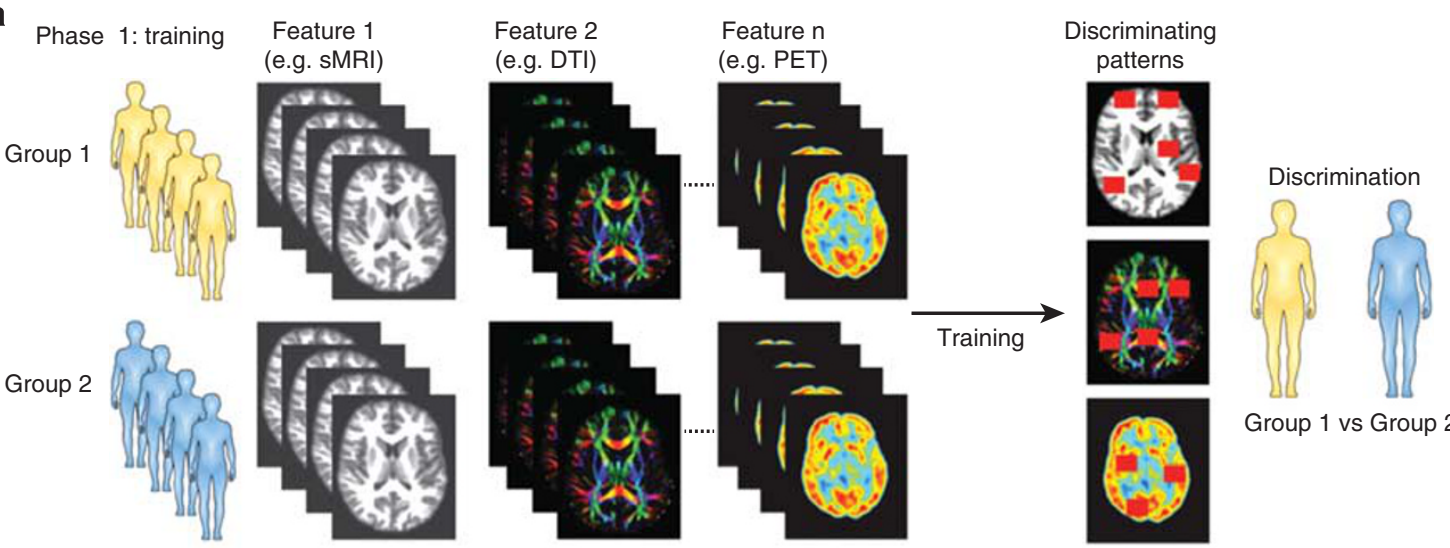

Group 2
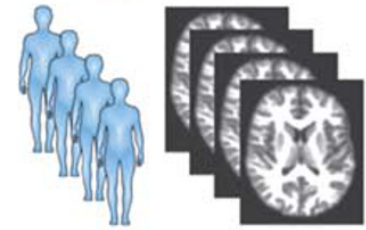

b
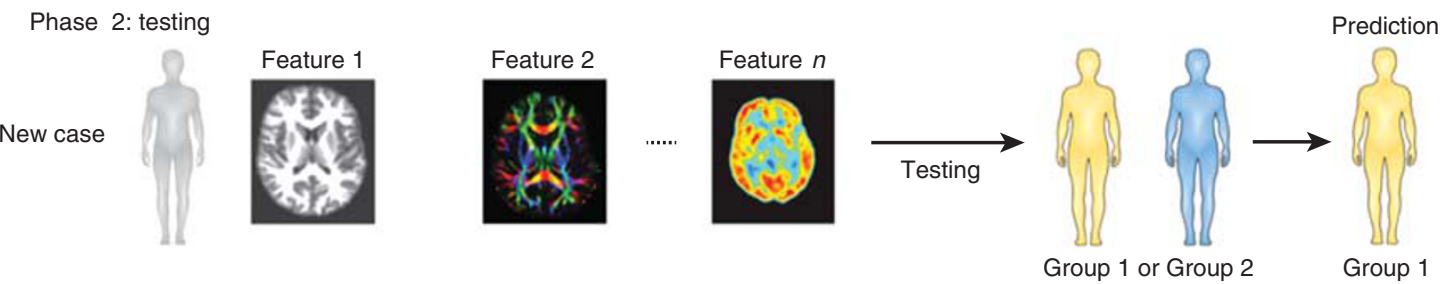

Figure 4. Machine learning. (a) During the first phase, the classifier is trained on neuroimaging data such as sMRI, DTI, or positron emission tomography (PET), from two groups of participants (eg, neurotypical individuals and individuals with ASD). During training, patterns within the neuroimaging data that best discriminate between groups are identified. (b) During the second phase, the classifier is provided with feature data from a new set of subjects and determines to which group each of the subjects belongs. CA is determined based on classifier performance in the testing phase. Reprinted from Ecker and Murphy (2014), with permission from Elsevier.

systems in ASD and more recent studies. First, recent studies have used rigorous motion-correction methods. Recently, it has been reported that even very small amounts of motion in resting state functional connectivity data (eg, Power et al, 2012; Van Dijk et al, 2012) and in structural dMRI data (Yendiki et al, 2013) can bias findings of group differences in connectivity metrics. These findings are crucial to the interpretation of reports of altered brain connectivity in ASD, as ASD cohorts may display increased amounts of motion related artifacts in their MRI data compared with neurotypical controls, and similarly, the degree of motion present in the data is likely to be correlated with subject age (Satterthwaite et al, 2013), producing a possible age and diagnostic status confound. A multitude of studies have recently been published speaking to how best to account for motion-related artifacts and aiming to identify the optimal series of processing steps for connectivity data analysis (eg, Carp, 2013; Hallquist et al, 2013; Power et al, 2012, 2013, 2014; Satterthwaite et al, 2013). On the heels of these reports, scientists have begun to revisit published results of connectivity-related findings in ASD, and in more recently published studies to analyze their data using a variety of processing streams. Other method-related choices such as use of low-pass filtering, seed selection, and whether connectivity results are obtained for the whole brain ( $v s$ within a priori ROIs) may also impact findings of overor under-connectivity in ASD (for a review, see Müller et al, 2011). Importantly, when analyzing data using a variety of suggested processing streams, findings of altered connectivity in children and adolescents with ASD appear to hold (eg, Maximo et al, 2013; Nair et al, 2014; Starck et al, 2013; Uddin et al, 2013).

A second cause of discrepant findings are differences in cohort age and severity among different studies. The trajectory of age-related development in both brain structure and function may be complex, not holding to a simple linear increase or decrease with increasing age. For example, Schumann et als (2004) work showing that the pattern of amygdala brain overgrowth seen early in life in ASD reverses later in development indicates that differences in sampling characteristics can lead to opposite findings. Ultimately, large-scale studies examining developmental trajectories will be essential if we are to understand how brain structure and function differ in ASD.

A third problem in brain imaging studies relates to the heterogeneity of the autism phenotype. The vast heterogeneity present in behavioral symptomatology and genetic liability to ASD likely reflects variation in disease etiology between diagnosed individuals (Geschwind 2009). Dissimilar disease etiology would additionally imply varied neurodevelopmental trajectories in ASD affected individuals. Discrepant findings in the neuroimaging literature may reflect variance in the severity of ASD symptomatology, the constellation of ASD behavioral symptoms represented, or the presence or absence of associated features such as mental retardation and severe language impairment. Furthermore, as described above, evidence suggests that the atypical functional brain responses to task stimuli in ASD may not simply be a result of a fundamental deficit in neural functioning, but rather, that incorporating extrinsic factors that increase attention or interest into neuroimaging task designs are associated with 
more normal activity (Hadjikhani et al, 2004; Perlman et al, 2011; Pierce et al, 2004; Pierce and Redcay 2008; Wang et al, 2007; Zürcher et al, 2013). Thus, discrepant findings in the neuroimaging literature may also be due to variation in sample characteristics or task demands. To address these issues, replication of previous findings will be essential.

\section{FUTURE DIRECTIONS AND CLINICAL IMPLICATIONS}

Although neuroimaging techniques allow us to relate behavioral traits and genetic risks to structural and functional brain development, an important question in autism neuroimaging research is whether findings of altered brain activity and connectivity during childhood, adolescence, and adulthood are the cause of, or the result of ASD behavioral pathology. Experience shapes brain structure, function, and connectivity; reduced social attention will affect a child's social experience, and the brain changes observed in older children may simply reflect this socially deprived experience. Recent advances in neuroimaging methods will allow researchers to begin to address some of these complex interactions by studying very young infants who are at high genetic risk for developing ASD, and by following individuals with ASD over time to map longterm neurodevelopmental trajectories. Our understanding of causality will be further guided by animal models, which can manipulate both genetic risk and experience to understand brain development in ASD, as well as large-scale neuroimaging data sharing projects designed to achieve sufficient power to detect true brain-gene-behavior relationships. Such work will be greatly enhanced by large-scale collaborations such as ABIDE (Di Martino et al, 2014) and NDAR (the National Database for Autism Research), combining imaging data from multiple sites and integrating these data with both genetic and behavioral data. Given the correlational nature of imaging and genetic methods, causality can only begin to be addressed in the context of longitudinal studies of both affected and unaffected individuals with different genetic vulnerability for ASD. Recently, neuroimaging studies have begun to assess brain structure and function in unaffected family members of individuals with ASD. By mapping developmental trajectories in unaffected siblings, we may also gain insight into possible genetic and neurodevelopmental protective factors and critical periods during which such factors come on line.

Understanding developmental trajectories will be essential, both for understanding brain development in heterogeneous subgroups of individuals with ASD, as well as for determining the impact of treatment on brain structure and function in these populations. As the infant brain is very plastic and adaptable, early interventions should help to shape the emerging activity and connectivity patterns that experience helps to create. As our technologies improve, brain imaging may allow us to measure the impact of interventions on brain development, as well as to inform the choice of optimal interventions. With the increasing move toward imaging infants and toddlers at-risk for autism, we should be able to identify abnormal neurodevelopmental trajectories and guide intervention strategies that will be most effective at this stage of greatest brain plasticity.

Any application of neuroimaging data to aid in diagnosis and treatment will ultimately rely on the ability to accurately identify children at-risk for developing ASD. A major question is whether differences in neuroimaging measures (which are typically interpreted at the group level) are robust at the individual subject level, a prerequisite for identifying and developing treatment options for individuals at high risk for ASD. Recent advances in data analytic methods, such as machine learning classification techniques that allow for integration of information across multiple modalities (eg, Ingalhalikar et al, 2012) and identification of sub-populations within a heterogeneous population (eg, Filipovych et al, 2012), may be able to identify the most relevant signatures of ASD from neuroimaging, genetic, and behavioral data in order to accurately predict diagnostic status, treatment response, and/or developmental outcome at the individual level.

\section{FUNDING AND DISCLOSURE}

The authors declare no conflict of interest.

\section{ACKNOWLEDGEMENTS}

The authors receive funding from Autism Centers of Excellence grants (2P50 HD055784 NIH- NICHD and 1R01 HD073983-01 NIH/NICHD), the Staglin Center for Cognitive Neurosciences (SB), the Ahmanson-Lovelace Brain Mapping Center (MD), Medical Scientist Training Program (T32 GM008042) (JDR), Neurobehavioral Genetics Training Program (5T32 MH073526-08 NIH) (LMH), National Research Service Award (F31 MH093999-01A1) (SAG).

\section{REFERENCES}

Abrams DA, Lynch CJ, Cheng KM, Phillips J, Supekar K, Ryali S et al (2013). Underconnectivity between voice-selective cortex and reward circuitry in children with autism. Proc Natl Acad Sci USA 110: 12060-12065. Provides neuroimaging evidence for the social motivation hypothesis of ASD, demonstrating functional underconnectivity between voice-selective, reward processing, and emotional learning brain regions during resting state.

Agam Y, Joseph RM, Barton JJ, Manoach DS (2010). Reduced cognitive control of response inhibition by the anterior cingulate cortex in autism spectrum disorders. Neuroimage 52: 336-347.

Alexander AL, Lee JE, Lazar M, Boudos R, DuBray MB, Oakes TR et al (2007). Diffusion tensor imaging of the corpus callosum in Autism. Neuroimage 34 61-73.

Amaral DG, Schumann CM, Nordahl CW (2008). Neuroanatomy of autism. Trends Neurosci 31: 137-145.

American Psychiatric Association (2013). Diagnostic and Statistical Manual of Mental Disorders. 5th edn, American Psychiatric Publishing.

Anderson JS, Nielsen JA, Froehlich AL, DuBray MB, Druzgal TJ, Cariello AN et al (2011). Functional connectivity magnetic resonance imaging classification of autism. Brain 134(Part 12): 3742-3754.

Andrews MW, Rosenblum LA (1993). Live-social-video reward maintains joystick task performance in bonnet macaques. Percept Mot Skills 77: 755-763.

Andrews MW, Rosenblum LA (1994). Relative efficacy of video versus food-pellet reward of joystick tasks. Percept Mot Skills 78: 545-546. 
Assaf M, Jagannathan K, Calhoun VD, Miller L, Stevens MC, Sahl R et al (2010). Abnormal functional connectivity of default mode sub-networks in autism spectrum disorder patients. Neuroimage 53: 247-256.

Bailey A, Le Couteur A, Gottesman I, Bolton P, Simonoff E, Yuzda E et al (1995). Autism as a strongly genetic disorder: evidence from a British twin study. Psychol Med 25: 63-77.

Bailey A, Luthert P, Dean A, Harding B, Janota I, Montgomery M et al (1998). A clinicopathological study of autism. Brain 121(Part 5): 889-905.

Barnea-Goraly N, Kwon H, Menon V, Eliez S, Lotspeich L, Reiss AL (2004). White matter structure in autism: preliminary evidence from diffusion tensor imaging. Biol Psychiatry 55: 323-326.

Barnea-Goraly N, Lotspeich LJ, Reiss AL (2010). Similar white matter aberrations in children with autism and their unaffected siblings: a diffusion tensor imaging study using tract-based spatial statistics. Arch Gen Psychiatry 67: 1052-1060.

Baron-Cohen S (1991). The development of a theory of mind in autism: deviance and delay? Psychiatr Clin North Am 14: 33-51.

Baron-Cohen S, Hammer J (1997). Parents of children with Asperger syndrome: what is the cognitive phenotype? J Cogn Neurosci 9: 548-554.

Baron-Cohen S, Jolliffe T, Mortimore C, Robertson M (1997). Another advanced test of theory of mind: evidence from very high functioning adults with autism or Asperger syndrome. J Child Psychol Psychiatry 38: 813-822.

Baron-Cohen S, O'Riordan M, Stone V, Jones R, Plaisted K (1999). Recognition of faux pas by normally developing children and children with Asperger syndrome or high-functioning autism. J Autism Dev Disord 29: 407-418.

Baron-Cohen S, Wheelwright S, Hill J, Raste Y, Plumb I (2001). The 'reading the mind in the eyes' test revised version: a study with normal adults, and adults with asperger syndrome or high-functioning autism. J Child Psychol Psychiatry 42: 241-251.

Basser PJ, Pierpaoli C (1996). Microstructural and physiological features of tissues elucidated by quantitative-diffusion-tensor MRI. J Magn Reson 213: 560-570.

Bassett DS, Bullmore E, Verchinski BA, Mattay VS, Weinberger DR, MeyerLindenberg A (2008). Hierarchical organization of human cortical networks in health and schizophrenia. J Neurosci 28: 9239-9248.

Belin P, Zatorre RJ, Lafaille P, Ahad P, Pike B (2000). Voice-selective areas in human auditory cortex. Nature 403: 309-312.

Belmonte MK, Allen G, Beckel-Mitchener A, Boulanger LM, Carper RA, Webb SJ (2004). Autism and abnormal development of brain connectivity. J Neurosci 24: 9228-9231.

Bigler ED, Mortensen S, Neeley ES, Ozonoff S, Krasny L, Johnson M et al (2007). Superior temporal gyrus, language function, and autism. Dev Neuropsychol 31: 217-238.

Biswal B, Yetkin FZ, Haughton VM, Hyde JS (1995). Functional connectivity in the motor cortex of resting human brain using echo-planar MRI. Magn Reson Med 34: $537-541$

Blake R, Turner LM, Smoski MJ, Pozdol SL, Stone WL (2003). Visual recognition of biological motion is impaired in children with autism. Psychol Sci 14: 151-157.

Boddaert N, Chabane N, Gervais H, Good CD, Bourgeois M, Plumet MH et al (2004). Superior temporal sulcus anatomical abnormalities in childhood autism: a voxel-based morphometry MRI study. Neuroimage 23: 364-369.

Bode MK, Mattila ML, Kiviniemi V, Rahko J, Moilanen I, Ebeling H et al (2011). White matter in autism spectrum disorders - evidence of impaired fiber formation. Acta Radiol 52: 1169-1174.

Bolling DZ, Pitskel NB, Deen B, Crowley MJ, McPartland JC, Mayes LC et al (2011). Dissociable brain mechanisms for processing social exclusion and rule violation. Neuroimage 54: 2462-2471

Bonilha L, Cendes F, Rorden C, Eckert M, Dalgalarrondo P, Li LM et al (2008). Gray and white matter imbalance-typical structural abnormality underlying classic autism? Brain Dev 30: 396-401.

Bookheimer SY, Wang AT, Scott A, Sigman M, Dapretto M (2008). Frontal contributions to face processing differences in autism: evidence from fMRI of inverted face processing. J Int Neuropsychol Soc 14: 922-932.

Boucher J (2003). Language development in autism. Int J Pediatr Otorhinolaryngol 67(Suppl 1): S159-S163.

Brothers $L$ (1990). The neural basis of primate social communication. Motiv Emot 14: 81-91.

Bruce C, Desimone R, Gross C (1981). Visual properties of neurons in a polysensory area in superior temporal sulcus of macaque. J Neurophysiol 46: 369-384.

Buckner RL, Andrews-Hanna JR, Schacter DL (2008). The brain's default network: anatomy, function, and relevance to disease. Ann N Y Acad of Sci 1124: 1-38. Reviews evidence for the default mode network and functional importance of consistent brain networks during rest.

Buckner RL, Krienen FM, Yeo BT (2013). Opportunities and limitations of intrinsic functional connectivity MRI. Nat Neurosci 16: 832-837.
Bullmore E, Sporns O (2009). Complex brain networks: graph theoretical analysis of structural and functional systems. Nat Rev Neurosci 10: 186-198.

Calhoun VD, Kiehl KA, Pearlson GD (2008). Modulation of temporally coherent brain networks estimated using ICA at rest and during cognitive tasks. Hum Brain Mapp 29: 828-838.

Carp J (2013). Optimizing the order of operations for movement scrubbing: comment on Power et al. Neuroimage 76: 436-438.

Carper RA, Moses P, Tigue ZD, Courchesne E (2002). Cerebral lobes in autism: early hyperplasia and abnormal age effects. Neuroimage 16: 1038-1051.

Carter EJ, Pelphrey KA (2006). School-aged children exhibit domain-specific responses to biological motion. Soc Neurosci 1: 396-411.

Cascio CJ, Foss-Feig JH, Heacock J, Schauder KB, Loring WA, Rogers BP et al (2014). Affective neural response to restricted interests in autism spectrum disorders. J Child Psychol Psychiatry 55: 162-171. Demonstrates a neural basis for restricted interests in ASD, and shows that children with ASD lack the typical neural affective response to others' interests

Cascio CJ, Moana-Filho EJ, Guest S, Nebel MB, Weisner J, Baranek GT et al (2012). Perceptual and neural response to affective tactile texture stimulation in adults with autism spectrum disorders. Autism Res 5: 231-244.

Castelli F, Frith C, Happé F, Frith U (2002). Autism, Asperger syndrome and brain mechanisms for the attribution of mental states to animated shapes. Brain 125(Part 8): 1839-1849.

Center for Disease Control (2014). Prevalence of autism spectrum disorder among children aged 8 years-autism and developmental disabilities monitoring network, 11 sites, United States, 2010. MMWR 63: 1-21.

Chawarska K, Klin A, Volkmar F (2003). Automatic attention cueing through eye movement in 2-year-old children with autism. Child Dev 74: 1108-1122.

Chawarska K, Volkmar F, Klin A (2010). Limited attentional bias for faces in toddlers with autism spectrum disorders. Arch Gen Psychiatry 67: 178-185.

Chen R, Jiao Y, Herskovits EH (2011). Structural MRI in autism spectrum disorder. Pediatr Res 69(Part 2): 63R-68R.

Cheng Y, Chou KH, Chen IY, Fan YT, Decety J, Lin CP (2010). Atypical development of white matter microstructure in adolescents with autism spectrum disorders. Neuroimage 50: 873-882.

Cheon KA, Kim YS, Oh SH, Park SY, Yoon HW, Herrington J et al (2011). Involvement of the anterior thalamic radiation in boys with high functioning autism spectrum disorders: a Diffusion Tensor Imaging Study. Brain Res 1417: 77-86.

Cherkassky VL, Kana RK, Keller TA, Just MA (2006). Functional connectivity in a baseline resting-state network in autism. Neuroreport 17: 1687-1690.

Cheung C, Chua SE, Cheung V, Khong PL, Tai KS, Wong TK et al (2009). White matter fractional anisotrophy differences and correlates of diagnostic symptoms in autism. J Child Psychol Psychiatry 50: 1102-1112.

Chevallier C, Kohls G, Troiani V, Brodkin ES, Schultz RT (2012). The social motivation theory of autism. Trends Cogn Sci 16: 231-239.

Chiang MC, McMahon KL, de Zubicaray GI, Martin NG, Hickie I, Toga AW et al (2011). Genetics of white matter development: a DTI study of 705 twins and their siblings aged 12 to 29. Neuroimage 54: 2308-2317.

Clemm von Hohenberg C, Wigand MC, Kubicki M, Leicht G, Giegling I, Karch S et al (2013). CNTNAP2 polymorphisms and structural brain connectivity: a diffusion-tensor imaging study. J Psychiatr Res 47: 1349-1356.

Colich NL, Wang AT, Rudie JD, Hernandez LM, Bookheimer SY, Dapretto M (2012). Atypical neural processing of ironic and sincere remarks in children and adolescents with autism spectrum disorders. Metaphor Symb 27: 70-92.

Corbett BA, Carmean V, Ravizza S, Wendelken C, Henry ML, Carter C et al (2009). A functional and structural study of emotion and face processing in children with autism. Psychiatry Res 173: 196-205.

Courchesne E, Karns CM, Davis HR, Ziccardi R, Carper RA, Tigue ZD et al (2001). Unusual brain growth patterns in early life in patients with autistic disorder: an MRI study. Neurology 57: 245-254.

Courchesne E, Pierce K (2005). Why the frontal cortex in autism might be talking only to itself: local over-connectivity but long-distance disconnection. Curr Opin Neurobio/ 15: 225-230. Reviews evidence for local over-connectivity versus long-distance under-connectivity in ASD and proposes a developmental model for these abnormalities.

Courchesne E, Pierce K, Schumann CM, Redcay E, Buckwalter JA, Kennedy DP et al (2007). Mapping early brain development in autism. Neuron 56: 399-413. Review of neurobiological findings during the first years of life in ASD and discussion of theories for how these early abnormalities may lead to core deficits in ASD.

Courchesne E, Saitoh O, Yeung-Courchesne R, Press GA, Lincoln AJ, Haas RH et al (1994). Abnormality of cerebellar vermian lobules VI and VII in patients with infantile autism: identification of hypoplastic and hyperplastic subgroups with MR imaging. AJR Am J Roentgenol 162: 123-130.

Courchesne E, Yeung-Courchesne R, Press GA, Hesselink JR, Jernigan TL (1988). Hypoplasia of cerebellar vermal lobules VI and VII in autism. N Engl J Med 318: 1349-1354. 
Craddock RC, Jbabdi S, Yan CG, Vogelstein JT, Castellanos FX, Di Martino A et al (2013). Imaging human connectomes at the macroscale. Nat Methods 10: 524-539.

Critchley HD, Daly EM, Bullmore ET, Williams SC, Van Amelsvoort T, Robertson DM et al (2000). The functional neuroanatomy of social behaviour: changes in cerebral blood flow when people with autistic disorder process facial expressions. Brain 123(Part 11): 2203-2212.

Dalton KM, Nacewicz BM, Johnstone T, Schaefer HS, Gernsbacher MA, Goldsmith $\mathrm{HH}$ et al (2005). Gaze fixation and the neural circuitry of face processing in autism. Nat Neurosci 8: 519-526. First study to show that amygdala responses to faces in ASD is moderated by variation in eye fixation: individuals with greater gaze to the eyes had heightened amygdala response.

Dapretto M, Davies MS, Pfeifer JH, Scott AA, Sigman M, Bookheimer SY et al (2006). Understanding emotions in others: mirror neuron dysfunction in children with autism spectrum disorders. Nat Neurosci 9: 28-30.

Davies MS, Dapretto M, Sigman M, Sepeta L, Bookheimer SY (2011). Neural bases of gaze and emotion processing in children with autism spectrum disorders. Brain Behav 1: 1-11.

Deaner RO, Khera AV, Platt ML (2005). Monkeys pay per view: adaptive valuation of social images by rhesus macaques. Curr Biol 15: 543-548.

Delmonte S, Balsters JH, McGrath J, Fitzgerald J, Brennan S, Fagan AJ et al (2012). Social and monetary reward processing in autism spectrum disorders. Mol Autism 3: 7 .

Dennis EL, Jahanshad N, Rudie JD, Brown JA, Johnson K, McMahon KL et al (2011). Altered structural brain connectivity in healthy carriers of the autism risk gene, CNTNAP2. Brain Connect 1: 447-459.

Desimone R, Albright TD, Gross CG, Bruce C (1984). Stimulus-selective properties of inferior temporal neurons in the macaque. J Neurosci 4: 2051-2062.

Di Martino A, Ross K, Uddin LQ, Sklar AB, Castellanos FX, Milham MP (2009). Functional brain correlates of social and nonsocial processes in autism spectrum disorders: an activation likelihood estimation meta-analysis. Biol Psychiatry 65 63-74.

Di Martino A, Yan CG, Li Q, Denio E, Castellanos FX, Alaerts K et al (2014). The autism brain imaging data exchange: towards a large-scale evaluation of the intrinsic brain architecture in autism. Mol Psychiatry 19: 659-667. Introduces ABIDE brain imaging consortium and helps to reconcile disparate findings in connectivity research in ASD.

di Pellegrino G, Fadiga L, Fogassi L, Gallese V, Rizzolatti G (1992). Understanding motor events: a neurophysiological study. Exp Brain Res 91: 176-180.

Dichter GS (2012). Functional magnetic resonance imaging of autism spectrum disorders. Dialogues Clin Neurosci 14: 319-351.

Dichter GS, Richey JA, Rittenberg AM, Sabatino A, Bodfish JW (2012). Reward circuitry function in autism during face anticipation and outcomes. J Autism Dev Disord 42: 147-160.

Ecker C, Murphy D (2014). Neuroimaging in autism-from basic science to translational research. Nat Rev Neurol 10: 82-91.

Ecker C, Rocha-Rego V, Johnston P, Mourao-Miranda J, Marquand A, Daly EM et al MRC AIMS Consortium (2010). Investigating the predictive power of whole-brain structural MR scans in autism; a pattern classification approach. Neuroimage 49: 44-56.

Egaas B, Courchesne E, Saitoh O (1995). Reduced size of corpus callosum in autism. Arch Neurol 52: 794-801.

Elison JT, Paterson SJ, Wolff JJ, Reznick JS, Sasson NJ, Gu H et allBIS Network (2013). White matter microstructure and atypical visual orienting in 7-month-olds at risk for autism. Am J Psychiatry 170: 899-908.

Fair DA, Cohen AL, Power JD, Dosenbach NU, Church JA, Miezin FM et al (2009). Functional brain networks develop from a 'local to distributed' organization. PLoS Comput Biol 5: e1000381. Reviews typical development of connectivity within large-scale brain networks.

Fantz RL (1963). Pattern vision in newborn infants. Science 140: 296-297.

Febo M, Numan M, Ferris CF (2005). Functional magnetic resonance imaging shows oxytocin activates brain regions associated with mother-pup bonding during suckling. J Neurosci 25: 11637-11644.

Ferrari PF, Rozzi S, Fogassi L (2005). Mirror neurons responding to observation of actions made with tools in monkey ventral premotor cortex. J Cogn Neurosci 17: 212-226.

Filipovych R, Resnick SM, Davatzikos C (2012). JointMMCC: joint maximum-margin classification and clustering of imaging data. IEEE Trans Med Imaging 31: 1124-1140.

Fogassi L, Ferrari PF, Gesierich B, Rozzi S, Chersi F, Rizzolatti G (2005). Parietal lobe: from action organization to intention understanding. Science 308: 662-667.

Fornito A, Zalesky A, Bassett DS, Meunier D, Ellison-Wright I, Yücel M et al (2011). Genetic influences on cost-efficient organization of human cortical functional networks. J Neurosci 31: 3261-3270.
Fox M, Raichle ME (2007). Spontaneous fluctuations in brain activity observed with functional magnetic resonance imaging. Nat Rev Neurosci 8: 700-711.

Fox MD, Greicius M (2010). Clinical applications of resting state functional connectivity. Front Syst Neurosci 4: 19.

Freitag CM, Konrad C, Häberlen M, Kleser C, von Gontard A, Reith W et al (2008). Perception of biological motion in autism spectrum disorders. Neuropsychologia 46: $1480-1494$

Freitag CM, Luders E, Hulst HE, Narr KL, Thompson PM, Toga AW et al (2009). Total brain volume and corpus callosum size in medication-naïve adolescents and young adults with autism spectrum disorder. Biol Psychiatry 66: 316-319.

Frith CD, Frith U (1999). Interacting minds-a biological basis. Science 286 : 1692-1695.

Gaffrey MS, Kleinhans NM, Haist F, Akshoomoff N, Campbell A, Courchesne E et al (2007). Atypical participation of visual cortex during word processing in autism: an fMRI study of semantic decision. Neuropsychologia 45: 1672-1684.

Gallagher HL, Happé F, Brunswick N, Fletcher PC, Frith U, Frith CD (2000). Reading the mind in cartoons and stories: an fMRI study of 'theory of mind' in verbal and nonverbal tasks. Neuropsychologia 38: 11-21.

Gervais H, Belin P, Boddaert N, Leboyer M, Coez A, Sfaello I et al (2004). Abnormal cortical voice processing in autism. Nat Neurosci 7: 801-802.

Geschwind DH (2009). Advances in autism. Ann Rev Med 60: 367-380.

Geschwind DH, Levitt P (2007). Autism spectrum disorders: developmental disconnection syndromes. Curr Opin Neurobiol 17: 103-111. Proposes a developmental model that combines genetic and imaging findings to potentially explain brain underconnectivity in ASD and incorporates withingroup heterogeneity.

Glahn DC, Winkler AM, Kochunov P, Almasy L, Duggirala R, Carless MA et al (2010). Genetic control over the resting brain. Proc Natl Acad Sci USA 107: 1223-1228.

Golan O, Baron-Cohen S, Hill JJ, Rutherford MD (2007). The 'reading the mind in the voice' test-revised: a study of complex emotion recognition in adults with and without autism spectrum conditions. J Autism Dev Disord 37: 1096-1106.

Goren CC, Sarty M, Wu PY (1975). Visual following and pattern discrimination of face-like stimuli by newborn infants. Pediatrics 56: 544-549.

Green SA, Rudie JD, Colich NL, Wood JJ, Shirinyan D, Hernandez L et al (2013). Overreactive brain responses to sensory stimuli in youth with autism spectrum disorders. J Am Acad Child Adolesc Psychiatry 52: 1158-1172. First study to examine the neurobiological basis of sensory over-responsivity in ASD; takes into account heterogeneity in sensory responsiveness.

Grill-Spector K, Knouf N, Kanwisher N (2004). The fusiform face area subserves face perception, not generic within-category identification. Nat Neurosci 7: 555-562.

Groen WB, Zwiers MP, van der Gaag RJ, Buitelaar JK (2008). The phenotype and neural correlates of language in autism: an integrative review. Neurosci Biobehav Rev 32: 1416-1425.

Guyer AE, Monk CS, McClure-Tone EB, Nelson EE, Roberson-Nay R, Adler AD et al (2008). A developmental examination of amygdala response to facial expressions. J Cogn Neurosci 20: 1565-1582.

Hadjikhani N, Joseph RM, Snyder J, Chabris CF, Clark J, Steele S et al (2004). Activation of the fusiform gyrus when individuals with autism spectrum disorder view faces. Neuroimage 22: 1141-1150.

Hadjikhani N, Joseph RM, Snyder J, Tager-Flusberg H (2006). Anatomical differences in the mirror neuron system and social cognition network in autism. Cereb Cortex 16: 1276-1282.

Hagmann P, Sporns O, Madan N, Cammoun L, Pienaar R, Wedeen VJ et al (2010). White matter maturation reshapes structural connectivity in the late developing human brain. Proc Natl Acad Sci USA 107: 19067-19072.

Hallquist MN, Hwang K, Luna B (2013). The nuisance of nuisance regression: spectral misspecification in a common approach to resting-state fMR preprocessing reintroduces noise and obscures functional connectivity. Neuroimage 82: 208-225.

Hardan AY, Pabalan M, Gupta N, Bansal R, Melhem NM, Fedorov S et al (2009). Corpus callosum volume in children with autism. Psychiatry Res 174: 57-61.

Hariri AR, Weinberger DR (2003). Imaging genomics. Br Med Bull 65: 259-270. A clear review of the imaging genetics approach to neuroimaging data analysis.

Harris GJ, Chabris CF, Clark J, Urban T, Aharon I, Steele S et al (2006). Brain activation during semantic processing in autism spectrum disorders via functional magnetic resonance imaging. Brain Cogn 61: 54-68.

Hazlett HC, Poe M, Gerig G, Smith RG, Provenzale J, Ross A et al (2005). Magnetic resonance imaging and head circumference study of brain size in autism: birth through age 2 years. Arch Gen Psychiatry 62: 1366-1376.

Hazlett HC, Poe MD, Gerig G, Smith RG, Piven J (2006). Cortical gray and white brain tissue volume in adolescents and adults with autism. Biol Psychiatry 59: 1-6.

Hedrick A, Lee Y, Wallace GL, Greenstein D, Clasen L, Giedd JN et al (2012). Autism risk gene MET variation and cortical thickness in typically developing children and adolescents. Autism Res 5: 434-439. 
Herbert MR, Ziegler DA, Deutsch CK, O'Brien LM, Lange N, Bakardjiev A et al (2003; Dissociations of cerebral cortex, subcortical and cerebral white matter volumes in autistic boys. Brain 126(Part 5): 1182-1192. Provides evidence for specific developmental pattern of abnormal white matter overgrowth in ASD.

Herrington JD, Baron-Cohen S, Wheelwright SJ, Singh KD, Bullmore ET, Brammer M et al (2007). The role of MT + N5 during biological motion perception in Asperger Syndrome: an fMRI study. Res Autism Spectr Disord 1: 14-27.

Herrington JD, Nymberg C, Schultz RT (2011). Biological motion task performance predicts superior temporal sulcus activity. Brain and Cogn 77: 372-381.

Hesling I, Dilharreguy B, Peppé S, Amirault M, Bouvard M, Allard M (2010). The integration of prosodic speech in high functioning autism: a preliminary FMRI study. PloS One 5: e11571.

Hoehl S, Reid VM, Parise E, Handl A, Palumbo L, Striano T (2009). Looking at eye gaze processing and its neural correlates in infancy-implications for social development and autism spectrum disorder. Child Dev 80: 968-985.

Hoff GEA-J, Van den Heuvel MP, Benders MJ, Kersbergen KJ, De Vries LS (2013). On development of functional brain connectivity in the young brain. Front Hum Neurosci 7: 650

Hubl D, Bölte S, Feineis-Matthews S, Lanfermann H, Federspiel A, Strik W et al (2003). Functional imbalance of visual pathways indicates alternative face processing strategies in autism. Neurology 61: 1232-1237.

Huguet G, Ey E, Bourgeron T (2013). The genetic landscapes of autism spectrum disorders. Annu Rev Genomics Hum Genet 14: 191-213. Reviews the heterogeneous nature of ASD genetics.

Hyde KL, Samson F, Evans AC, Mottron L (2010). Neuroanatomical differences in brain areas implicated in perceptual and other core features of autism revealed by cortical thickness analysis and voxel-based morphometry. Hum Brain Mapp 31: 556-566.

lacoboni M, Lieberman MD, Knowlton BJ, Molnar-Szakacs I, Moritz M, Throop CJ et al (2004). Watching social interactions produces dorsomedial prefrontal and medial parietal BOLD $\mathrm{fMRI}$ signal increases compared to a resting baseline. Neuroimage 21: 1167-1173.

ngalhalikar M, Parker D, Bloy L, Roberts TP, Verma R (2011). Diffusion based abnormality markers of pathology: toward learned diagnostic predication of ASD. Neuroimage 57: 918-927.

Ingalhalikar M, Smith AR, Bloy L, Gur R, Roberts TP, Verma R (2012). Identifying sub-populations via unsupervised cluster analysis on multi-edge similarity graphs. Med Image Comput Comput Assist Interv 15(Part 2): 254-261.

Jiao Y, Chen R, Ke X, Chu K, Lu Z, Herskivits EH (2010). Predictive models of autism spectrum disorder based on brain regional thickness. Neuroimage 50: 589-599.

Juranek J, Filipek PA, Berenji GR, Modahl C, Osann K, Spence MA (2006). Association between amygdala volume and anxiety level: magnetic resonance imaging (MRI) study in autistic children. J Child Neurol 21: 1051-1058.

Just MA, Cherkassky VL, Keller TA, Kana RK, Minshew NJ (2007). Functional and anatomical cortical underconnectivity in autism: evidence from an FMRI study of an executive function task and corpus callosum morphometry. Cereb Cortex 17: 951-961.

Just MA, Cherkassky VL, Keller TA, Minshew NJ (2004). Cortical activation and synchronization during sentence comprehension in high-functioning autism: evidence of underconnectivity. Brain 127(Part 8): 1811-1821.

Kana RK, Keller TA, Cherkassky VL, Minshew NJ, Just MA (2006). Sentence comprehension in autism: thinking in pictures with decreased functional connectivity. Brain 129(Part 9): 2484-2493

Kana RK, Keller TA, Cherkassky VL, Minshew NJ, Just MA (2009). Atypical frontalposterior synchronization of theory of mind regions in autism during mental state attribution. Soc Neurosci 4: 135-152.

Kana RK, Keller TA, Minshew NJ, Just MA (2007). Inhibitory control in highfunctioning autism: decreased activation and underconnectivity in inhibition networks. Biol Psychiatry 62: 198-206.

Kana RK, Libero LE, Hu CP, Deshpande HD, Colburn JS (2014). Functional brain networks and white matter underlying theory-of-mind in autism. Soc Cogn Affect Neurosci 9: 98-105. A study examining neural abnormalities underlying theory of mind deficits in ASD; combines functional and structural imaging methods.

Keary CJ, Minshew NJ, Bansal R, Goradia D, Fedorov S, Keshavan MS et al (2009). Corpus callosum volume and neurocognition in autism. J Autism Dev Disord 39: 834-841.

Keller TA, Kana RK, Just MA (2007). A developmental study of the structural integrity of white matter in autism. Neuroreport 18: 23-27.

Kennedy DP, Courchesne E (2008a). Functional abnormalities of the default network during self- and other-reflection in autism. Soc Cogn Affect Neurosci 3: 177-190.

Kennedy DP, Courchesne E (2008b). The intrinsic functional organization of the brain is altered in autism. Neuroimage 39: 1877-1885.
Keown CL, Shih P, Nair A, Peterson N, Mulvey ME, Müller RA (2013). Local functional overconnectivity in posterior brain regions is associated with symptom severity in autism spectrum disorders. Cell Rep 5: 567-572.

Klei L, Sanders SJ, Murtha MT, Hus V, Lowe JK, Willsey AJ et al (2012). Common genetic variants, acting additively, are a major source of risk for autism. Mol Autism 3: 9.

Kleinhans NM, Müller RA, Cohen DN, Courchesne E (2008a). Atypical functional lateralization of language in autism spectrum disorders. Brain Res 1221: $115-125$

Kleinhans NM, Richards T, Johnson LC, Weaver KE, Greenson J, Dawson G et al (2011). fMRI evidence of neural abnormalities in the subcortical face processing system in ASD. Neuroimage 54: 697-704.

Kleinhans NM, Richards T, Sterling L, Stegbauer KC, Mahurin R, Johnson LC et al (2008b). Abnormal functional connectivity in autism spectrum disorders during face processing. Brain 131(Part 4): 1000-1012.

Kleinhans NM, Richards T, Weaver K, Johnson LC, Greenson J, Dawson G et al (2010). Association between amygdala response to emotional faces and social anxiety in autism spectrum disorders. Neuropsychologia 48: 3665-3670.

Klin A, Lin DJ, Gorrindo P, Ramsay G, Jones W (2009). Two-year-olds with autism orient to non-social contingencies rather than biological motion. Nature 459: 257-261.

Klöppel S, Abdulkadir A, Jack CR Jr, Koutsouleris N, Mourão-Miranda J, Vemuri P. (2012). Diagnostic neuroimaging across diseases. Neuroimage 61: 457-463.

Knaus TA, Silver AM, Kennedy M, Lindgren KA, Dominick KC, Siegel J et al (2010). Language laterality in autism spectrum disorder and typical controls: a functional, volumetric, and diffusion tensor MRI study. Brain Lang 112: 113-120.

Kochunov P, Glahn DC, Lancaster JL, Winkler AM, Smith S, Thompson PM et al (2010). Genetics of microstructure of cerebral white matter using diffusion tensor imaging. Neuroimage 53: 1109-1116.

Kohls G, Schulte-Rüther M, Nehrkorn B, Müller K, Fink GR, Kamp-Becker I et al (2013). Reward system dysfunction in autism spectrum disorders. Soc Cogn Affect Neurosci 8: 565-572.

Koldewyn K, Whitney D, Rivera SM (2011). Neural correlates of coherent and biological motion perception in autism. Dev Sci 14: 1075-1088.

Koshino H, Carpenter PA, Minshew NJ, Cherkassky VL, Keller TA, Just MA (2005). Functional connectivity in an fMRI working memory task in high-functioning autism. Neuroimage 24: 810-821.

Koten JW Jr, Wood G, Hagoort P, Goebel R, Propping P, Willmes K et al (2009). Genetic contribution to variation in cognitive function: an FMRI study in twins. Science 323: 1737-1740.

Legerstee M, Anderson D, Schaffer A (1998). Five- and eight-month-old infants recognize their faces and voices as familiar and social stimuli. Child Dev 69: 37-50.

Lenroot RK, Gogtay N, Greenstein DK, Wells EM, Wallace GL, Clasen LS et al (2007). Sexual dimorphism of brain developmental trajectories during childhood and adolescence. Neuroimage 36: 1065-1073.

Levitt JG, Blanton R, Capetillo-Cunliffe L, Guthrie D, Toga A, McCracken JT (1999). Cerebellar vermis lobules VIII-X in autism. Prog Neuropsychopharmacol Biol Psychiatry 23: 625-633.

Liss M, Saulnier C, Fein D, Kinsbourne M (2006). Sensory and attention abnormalities in autistic spectrum disorders. Autism 10: 155-172.

Lord C, Rutter M, Goode S, Heemsbergen J, Jordan H, Mawhood L et al (1989). Autism diagnostic observation schedule: a standardized obersvation of communicative and social behavior. J Autism Dev Disord 19: 185-212.

Lévy F, Kendrick KM, Goode JA, Guevara-Guzman R, Keverne EB (1995). Oxytocin and vasopressin release in the olfactory bulb of parturient ewes: changes with maternal experience and effects on acetylcholine, gamma-aminobutyric acid, glutamate and noradrenaline release. Brain Res 669: 197-206.

Manes F, Piven J, Vrancic D, Nanclares V, Plebst C, Starkstein SE (1999). An MRI study of the corpus callosum and cerebellum in mentally retarded autistic individuals. J Neuropsychiatry Clin Neurosci 11: 470-474.

Mason RA, Williams DL, Kana RK, Minshew N, Just MA (2008). Theory of mind disruption and recruitment of the right hemisphere during narrative comprehension in autism. Neuropsychologia 46: 269-280.

Masten CL, Eisenberger NI, Borofsky LA, McNealy K, Pfeifer JH, Dapretto M (2011). Subgenual anterior cingulate responses to peer rejection: a marker of adolescents' risk for depression. Dev Psychopathol 23: 283-292.

Maximo JO, Keown CL, Nair A, Müller RA (2013). Approaches to local connectivity in autism using resting state functional connectivity MRI. Front Hum Neurosci 7: 605

McAlonan GM, Cheung V, Cheung C, Suckling J, Lam GY, Tai KS et al (2005). Mapping the brain in autism. A voxel-based MRI study of volumetric differences and intercorrelations in autism. Brain 128(Part 2): 268-276.

McCann J, Peppé S, Gibbon FE, O'Hare A, Rutherford M (2007). Prosody and its relationship to language in school-aged children with high-functioning autism. Int J Lang Commun Disord 42: 682-702. 
Mizuno A, Villalobos ME, Davies MM, Dahl BC, Müller RA (2006). Partially enhanced thalamocortical functional connectivity in autism. Brain Res 1104: 160-174.

Mondloch CJ, Lewis TL, Budreau DR, Maurer D, Dannemiller JL, Stephens BR et al (1999). Face perception during early infancy. Psychol Sci 10: 419-422.

Monk CS, Peltier SJ, Wiggins JL, Weng SJ, Carrasco M, Risi S et al (2009). Abnormalities of intrinsic functional connectivity in autism spectrum disorders. Neuroimage 47: 764-772.

Mori S, Zhang J (2006). Principles of diffusion tensor imaging and its applications to basic neuroscience research. Neuron 51: 527-539.

Morris JP, Pelphrey KA, McCarthy G (2008). Perceived causality influences brain activity evoked by biological motion. Soc Neurosci 3: 16-25.

Mundy P, Sullivan L, Mastergeorge AM (2009). A parallel and distributed-processing model of joint attention, social cognition and autism. Autism Res 2: 2-21.

Munson J, Dawson G, Abbott R, Faja S, Webb SJ, Friedman SD et al (2006). Amygdalar volume and behavioral development in autism. Arch Gen Psychiatry 63: 686-693

Müller RA, Shih P, Keehn B, Deyoe JR, Leyden KM, Shukla DK (2011). Underconnected, but how? A survey of functional connectivity MRI studies in autism spectrum disorders. Cereb Cortex 21: 2233-2243.

Nair A, Keown CL, Datko M, Shih P, Keehn B, Müller RA (2014). Impact of methodological variables on functional connectivity findings in autism spectrum disorders. Hum Brain Mapp 35: 4035-4048. Review of functional connectivity methods and their differing impacts on findings; helps explain discrepant functional connectivity findings in ASD.

Nickl-Jockschat T, Habel U, Michel TM, Manning J, Laird AR, Fox PT et al (2012). Brain structure anomalies in autism spectrum disorder-a meta-analysis of VBM studies using anatomic likelihood estimation. Hum Brain Mapp 33: 1470-1489.

Nielsen JA, Zielinski BA, Fletcher PT, Alexander AL, Lange N, Bigler ED et al (2013). Multisite functional connectivity classification of autism: ABIDE results. Front Hum Neurosci 7: 599.

Nieminen-von Wendt T, Metsähonkala L, Kulomäki T, Aalto S, Autti T, Vanhala R et al (2003). Changes in cerebral blood flow in Asperger syndrome during theory of mind tasks presented by the auditory route. Eur Child Adolesc Psychiatry 12: 178-189.

Noonan SK, Haist F, Müller RA (2009). Aberrant functional connectivity in autism: evidence from low-frequency BOLD signal fluctuations. Brain Res 1262: 48-63.

Nordenbæk C, Jørgensen M, Kyvik KO, Bilenberg N (2014). A Danish populationbased twin study on autism spectrum disorders. Eur Child Adolesc Psychiatry 23: $35-43$.

Osterling J, Dawson G (1994). Early recognition of children with autism: a study of first birthday home videotapes. J Autism Dev Disord 24: 247-257.

Osterling JA, Dawson G, Munson JA (2002). Early recognition of 1-year-old infants with autism spectrum disorder versus mental retardation. Dev Psychopathol 14 239-251.

O'Doherty J, Kringelbach ML, Rolls ET, Hornak J, Andrews C (2001). Abstract reward and punishment representations in the human orbitofrontal cortex. Nat Neurosci 4: 95-102.

O'Doherty JP, Deichmann R, Critchley HD, Dolan RJ (2002). Neural responses during anticipation of a primary taste reward. Neuron 33: 815-826.

Parikshak NN, Luo R, Zhang A, Won H, Lowe JK, Chandran V et al (2013). Integrative functional genomic analyses implicate specific molecular pathways and circuits in autism. Cell 155: 1008-1021. Review of ASD susceptibility genes and their role in cortical development

Pelphrey KA, Morris JP (2006). Brain mechanisms for interpreting the actions of others from biological-motion cues. Curr Dir Psychol Sci 15: 136-140.

Pelphrey KA, Morris JP, Michelich CR, Allison T, McCarthy G (2005). Functional anatomy of biological motion perception in posterior temporal cortex: an FMRI study of eye, mouth and hand movements. Cereb Cortex 15: 1866-1876.

Pelphrey KA, Shultz S, Hudac CM, Vander Wyk BC (2011). Research review: constraining heterogeneity: the social brain and its development in autism spectrum disorder. J Child Psychol Psychiatry 52: 631-644.

Peppé S, McCann J, Gibbon F, O'Hare A, Rutherford M (2007). Receptive and expressive prosodic ability in children with high-functioning autism. J Speech Lang Hear Res 50: 1015-1028.

Perlman SB, Hudac CM, Pegors T, Minshew NJ, Pelphrey KA (2011). Experimental manipulation of face-evoked activity in the fusiform gyrus of individuals with autism. Soc Neurosci 6: 22-30.

Perrett DI, Rolls ET, Caan W (1982). Visual neurones responsive to faces in the monkey temporal cortex. Exp Brain Res 47: 329-342.

Perrett DI, Smith PA, Potter DD, Mistlin AJ, Head AS, Milner AD et al (1985). Visual cells in the temporal cortex sensitive to face view and gaze direction. Proc $R$ Soc Lond B Biol Sci 223: 293-317.

Persico AM, Napolioni V (2013). Autism genetics. Behav Brain Res 251: 95-112.

Phillips ML, Bullmore ET, Howard R, Woodruff PW, Wright IC, Williams SC et al (1998). Investigation of facial recognition memory and happy and sad facial expression perception: an fMRI study. Psychiatry Res 83: 127-138.
Pierce K, Courchesne E (2001). Evidence for a cerebellar role in reduced exploration and stereotyped behavior in autism. Biol Psychiatry 49: 655-664.

Pierce K, Haist F, Sedaghat F, Courchesne E (2004). The brain response to personally familiar faces in autism: findings of fusiform activity and beyond. Brain 127(Part 12): 2703-2716.

Pierce K, Redcay E (2008). Fusiform function in children with an autism spectrum disorder is a matter of 'who'. Biol Psychiatry 64: 552-560.

Piggot J, Kwon H, Mobbs D, Blasey C, Lotspeich L, Menon V et al (2004). Emotional attribution in high-functioning individuals with autistic spectrum disorder: a functional imaging study. J Am Acad Child Adolesc Psychiatry 43 : 473-480

Piven J, Bailey J, Ranson BJ, Arndt S (1997). An MRI study of the corpus callosum in autism. Am J Psychiatry 154: 1051-1056.

Piven J, Nehme E, Simon J, Barta P, Pearlson G, Folstein SE (1992). Magnetic resonance imaging in autism: measurement of the cerebellum, pons, and fourth ventricle. Biol Psychiatry 31: 491-504.

Power JD, Barnes KA, Snyder AZ, Schlaggar BL, Petersen SE (2012). Spurious but systematic correlations in functional connectivity MRI networks arise from subject motion. Neuroimage 59: 2142-2154.

Power JD, Barnes KA, Snyder AZ, Schlaggar BL, Petersen SE (2013). Steps toward optimizing motion artifact removal in functional connectivity MRI; a reply to Carp. Neuroimage 76: 439-441.

Power JD, Mitra A, Laumann TO, Snyder AZ, Schlaggar BL, Petersen SE (2014). Methods to detect, characterize, and remove motion artifact in resting state fMRI. Neuroimage 84: 320-341.

Raznahan A, Lee Y, Vaituzis C, Tran L, Mackie S, Tiemeier H et al (2012). Allelic variation within the putative autism spectrum disorder risk gene homeobox $\mathrm{A} 1$ and cerebellar maturation in typically developing children and adolescents. Autism Res 5: 93-100.

Redcay E, Courchesne E (2008). Deviant functional magnetic resonance imaging patterns of brain activity to speech in 2-3-year-old children with autism spectrum disorder. Biol Psychiatry 64: 589-598.

Redcay E, Moran JM, Mavros PL, Tager-Flusberg H, Gabrieli JD, Whitfield-Gabrieli S (2013). Intrinsic functional network organization in high-functioning adolescents with autism spectrum disorder. Front Hum Neurosci 7: 573.

Rogers SJ, Ozonoff S (2005). Annotation: what do we know about sensory dysfunction in autism? A critical review of the empirical evidence. J Child Psychol Psychiatry 46: 1255-1268.

Rubinov M, Sporns O (2010). Complex network measures of brain connectivity: uses and interpretations. Neuroimage 52: 1059-1069. Review of methods for examining structural and functional brain connectivity

Rudie JD, Brown JA, Beck-Pancer D, Hernandez LM, Dennis EL, Thompson PM et al (2013). Altered functional and structural brain network organization in autism. Neuroimage Clin 2: 79-94.

Rudie JD, Dapretto M (2013). Convergent evidence of brain overconnectivity in children with autism? Cell Rep 5: 565-566. Focuses attention on discrepant findings of both over and under connectivity in ASD and discusses possible sample-related explanations for these discrepancies.

Rudie JD, Hernandez LM, Brown JA, Beck-Pancer D, Colich NL, Gorrindo P et al (2012a). Autism-associated promoter variant in MET impacts functional and structural brain networks. Neuron 75: 904-915. Demonstrates that an ASD risk gene is associated with abnormalities in both functional and structural brain networks in both neurotypical individuals and individuals with ASD.

Rudie JD, Shehzad Z, Hernandez LM, Colich NL, Bookheimer SY, lacoboni M et al (2012b). Reduced functional integration and segregation of distributed neural systems underlying social and emotional information processing in autism spectrum disorders. Cereb Cortex 22: 1025-1037.

Rutherford MD, Baron-Cohen S, Wheelwright S (2002). Reading the mind in the voice: a study with normal adults and adults with Asperger syndrome and high functioning autism. J Autism Dev Disord 32: 189-194.

Sato JR, Hoexter MQ, Oliveira PP Jr, Brammer MJ. MRC AIMS ConsortiumMurphy D, Ecker C (2013). Inter-regional cortical thickness correlations are associated with autistic symptoms: a machine-learning approach. J Psychiatr Res 47: 453-459.

Satterthwaite TD, Elliott MA, Gerraty RT, Ruparel K, Loughead J, Calkins ME et al (2013). An improved framework for confound regression and filtering for control of motion artifact in the preprocessing of resting-state functional connectivity data. Neuroimage 64: 240-256.

Satterthwaite TD, Wolf DH, Ruparel K, Erus G, Elliott MA, Eickhoff SB et al (2013). Heterogeneous impact of motion on fundamental patterns of developmental changes in functional connectivity during youth. Neuroimage 83: 45-57.

Sauer C, Montag C, Wörner C, Kirsch P, Reuter M (2012). Effects of a common variant in the CD38 gene on social processing in an oxytocin challenge study: possible links to autism. Neuropsychopharmacology 37: 1474-1482.

Saxe R, Kanwisher N (2003). People thinking about thinking people. The role of the temporo-parietal junction in 'theory of mind'. Neuroimage 19: 1835-1842. 
Saxe RR, Whitfield-Gabrieli S, Scholz J, Pelphrey KA (2009). Brain regions for perceiving and reasoning about other people in school-aged children. Child Dev 80: 1197-1209.

Schmitz N, Rubia K, van Amelsvoort T, Daly E, Smith A, Murphy DG (2008). Neural correlates of reward in autism. Br J Psychiatry 192: 19-24.

Schultz RT, Gauthier I, Klin A, Fulbright RK, Anderson AW, Volkmar F et al (2000). Abnormal ventral temporal cortical activity during face discrimination among individuals with autism and Asperger syndrome. Arch Gen Psychiatry 57: 331-340.

Schumann CM, Hamstra J, Goodlin-Jones BL, Lotspeich LJ, Kwon H, Buonocore MH et al (2004). The amygdala is enlarged in children but not adolescents with autism; the hippocampus is enlarged at all ages. J Neurosci 24: 6392-6401.

Scott-Van Zeeland AA, Abrahams BS, Alvarez-Retuerto AI, Sonnenblick LI, Rudie JD, Ghahremani D et al (2010). Altered functional connectivity in frontal lobe circuits is associated with variation in the autism risk gene CNTNAP2. Sci Transl Med 2: 56ra80. One of the first imaging genetics studies in ASD; demonstrates a relationship between brain connectivity and common genetic variants in an ASD risk gene.

Scott-Van Zeeland AA, Dapretto M, Ghahremani DG, Poldrack RA, Bookheimer SY (2010). Reward processing in autism. Autism Res 3: 53-67.

Seeley WW, Menon V, Schatzberg AF, Keller J, Glover GH, Kenna H et al (2007). Dissociable intrinsic connectivity networks for salience processing and executive control. J Neurosci 27: 2349-2356.

Shih P, Shen M, Ottl B, Keehn B, Gaffrey MS, Müller RA (2010). Atypical network connectivity for imitation in autism spectrum disorder. Neuropsychologia 48: 2931-2939.

Shukla DK, Keehn B, Smylie DM, Müller RA (2011). Microstructural abnormalities of short-distance white matter tracts in autism spectrum disorder. Neuropsychologia 49: 1378-1382

Simion F, Regolin L, Bulf $\mathrm{H}$ (2008). A predisposition for biological motion in the newborn baby. Proc Natl Acad Sci USA 105: 809-813.

Smith SM, Fox PT, Miller KL, Glahn DC, Fox PM, Mackay CE et al (2009). Correspondence of the brain's functional architecture during activation and rest. Proc Natl Acad Sci USA 106: 13040-13045.

Sparks BF, Friedman SD, Shaw DW, Aylward EH, Echelard D, Artru AA et al (2002). Brain structural abnormalities in young children with autism spectrum disorder. Neurology 59: 184-192.

Stanfield AC, Mclntosh AM, Spencer MD, Philip R, Gaur S, Lawrie SM (2008). Towards a neuroanatomy of autism: a systematic review and meta-analysis of structural magnetic resonance imaging studies. Eur Psychiatry 23: 289-299.

Starck T, Nikkinen J, Rahko J, Remes J, Hurtig T, Haapsamo H et al (2013). Resting state $\mathrm{fMRI}$ reveals a default mode dissociation between retrosplenial and medial prefrontal subnetworks in ASD despite motion scrubbing. Front Hum Neurosci 7: 802

Stevens MC, Pearlson GD, Calhoun VD (2009). Changes in the interaction of resting-state neural networks from adolescence to adulthood. Hum Brain Mapp 30: 2356-2366.

Stiegler KA, McDonald BC, Anand A, Saykin AJ, McDougle CJ (2011). Structural and functional magnetic resonance imaging of autism spectrum disorders. Brain Res 1380: 146-161.

Sundaram SK, Kumar A, Makki MI, Behen ME, Chugani HT, Chugani DC (2008). Diffusion tensor imaging of frontal lobe in autism spectrum disorder. Cereb Cortex 18: 2659-2665

Supekar K, Menon V, Rubin D, Musen M, Greicius MD (2008). Network analysis of intrinsic functional brain connectivity in Alzheimer's disease. PLoS Comput Biol 4: e1000100.

Supekar K, Uddin LQ, Khouzam A, Phillips J, Gaillard WD, Kenworthy LE et al (2013). Brain hyperconnectivity in children with autism and its links to social deficits. Cell Rep 5: 738-747.

Symons LA, Hains SM, Muir W (1998). Look at me: five-month-old infants' sensitivity to very small deviations in eye-gaze during social interactions. Infant Behav Dev 21: 531-536.

Tan GC, Doke TF, Ashburner J, Wood NW, Frackowiak RS (2010). Normal variation in fronto-occipital circuitry and cerebellar structure with an autism-associated polymorphism of CNTNAP2. Neuroimage 53: 1030-1042.

Tesink CM, Buitelaar JK, Petersson KM, van der Gaag RJ, Kan CC, Tendolkar I et al (2009). Neural correlates of pragmatic language comprehension in autism spectrum disorders. Brain 132(Part 7): 1941-1952.

Thut G, Schultz W, Roelcke U, Nienhusmeier M, Missimer J, Maguire RP et al (1997). Activation of the human brain by monetary reward. Neuroreport 8: 1225-1228.

Turner KC, Frost L, Linsenbardt D, Mcllroy JR, Müller RA (2006). Atypically diffuse functional connectivity between caudate nuclei and cerebral cortex in autism. Behav Brain Funct 2: 34
Uddin LQ, Menon V, Young CB, Ryali S, Chen T, Khouzam A et al (2011). Multivariate searchlight classification of structural magnetic resonance imaging in children and adolescents with autism. Biol Psychiatry 70: 833-841.

Uddin LQ, Supekar K, Lynch CJ, Khouzam A, Phillips J, Feinstein C et al (2013). Salience network-based classification and prediction of symptom severity in children with autism. JAMA Psychiatry 70: 869-879.

Uddin LQ, Supekar K, Menon V (2013). Reconceptualizing functional brain connectivity in autism from a developmental perspective. Front Hum Neurosci 7: 458. Demonstrates that functional connectivity in salience network can be used to discriminate children with and without ASD with high sensitivity and specificity.

van den Heuvel MP, Hulshoff Pol HE (2010). Exploring the brain network: a review on resting-state $\mathrm{fMRI}$ functional connectivity. Eur Neuropsychopharmacol 20: $519-534$

Van Dijk KR, Sabuncu MR, Buckner RL (2012). The influence of head motion on intrinsic functional connectivity MRI. Neuroimage 59: 431-438.

Verhoeven JS, De Cock P, Lagae L, Sunaert S (2010). Neuroimaging of autism. Neuroradiology 52: 3-14.

Villalobos ME, Mizuno A, Dahl BC, Kemmotsu N, Müller RA (2005). Reduced functional connectivity between $\mathrm{V} 1$ and inferior frontal cortex associated with visuomotor performance in autism. Neuroimage 25: 916-925.

Voineskos AN, Lett TA, Lerch JP, Tiwari AK, Ameis SH, Rajji TK et al (2011). Neurexin-1 and frontal lobe white matter: an overlapping intermediate phenotype for schizophrenia and autism spectrum disorders. PloS One 6: e20982.

von dem Hagen EA, Stoyanova RS, Baron-Cohen S, Calder AJ (2013). Reduced functional connectivity within and between 'social' resting state networks in autism spectrum conditions. Soc Cogn Affect Neurosci 8: 694-701.

von dem Hagen EA, Stoyanova RS, Rowe JB, Baron-Cohen S, Calder AJ (2013). Direct gaze elicits atypical activation of the theory-of-mind network in autism spectrum conditions. Cereb Cortex 24: 1485-1492.

Voos AC, Pelphrey KA, Kaiser MD (2013). Autistic traits are associated with diminished neural response to affective touch. Soc Cogn Affect Neurosci 8: 378-386.

Wang AT, Dapretto M, Hariri AR, Sigman M, Bookheimer SY (2004). Neural correlates of facial affect processing in children and adolescents with autism spectrum disorder. J Am Acad Child Adolesc Psychiatry 43: 481-490.

Wang AT, Lee SS, Sigman M, Dapretto M (2006). Neural basis of irony comprehension in children with autism: the role of prosody and context. Brain 129(Part 4): 932-943.

Wang AT, Lee SS, Sigman M, Dapretto M (2007). Reading affect in the face and voice: neural correlates of interpreting communicative intent in children and adolescents with autism spectrum disorders. Arch Gen Psychiatry 64: 698-708. A neuroimaging study with direct implications for intervention: shows that children with ASD have more typical patterns of brain response to communicative intent when given explicit instructions to attend to facial expression and tone of voice.

Wang J, Zuo X, He Y (2010). Graph-based network analysis of resting-state functional MRI. Front Syst Neurosci 4: 16.

Watts DJ, Strogatz SH (1998). Collective dynamics of 'small-world' networks. Nature 393: 440-442.

Weng SJ, Wiggins JL, Peltier SJ, Carrasco M, Risi S, Lord C et al (2010). Alterations of resting state functional connectivity in the default network in adolescents with autism spectrum disorders. Brain Res 1313: 202-214.

Whalley HC, O'Connell G, Sussmann JE, Peel A, Stanfield AC, Hayiou-Thomas ME et al (2011). Genetic variation in CNTNAP2 alters brain function during linguistic processing in healthy individuals. Am J Med Genet B Neuropsychiatr Genet 156B: 941-948.

Wolff JJ, Gu H, Gerig G, Elison JT, Styner M, Gouttard S et al IBIS Network (2012). Differences in white matter fiber tract development present from 6 to 24 months in infants with autism. Am J Psychiatry 169: 589-600.

Won H, Mah W, Kim E (2013). Autism spectrum disorder causes, mechanisms, and treatments: focus on neuronal synapses. Front Mol Neurosci 6: 19.

Yendiki A, Koldewyn K, Kakunoori S, Kanwisher N, Fischl B (2013). Spurious group differences due to head motion in a diffusion MRI study. Neuroimage $88 \mathrm{C}$ : 79-90.

Young LJ, Murphy Young AZ, Hammock EA (2005). Anatomy and neurochemistry of the pair bond. J Comp Neurol 493: 51-57.

Zhou Y, Yu F, Duong T (2014). Multiparametric MRI characterization and prediction in autism spectrum disorder using graph theory and machine learning. PLoS One 9: e90405

Zürcher NR, Donnelly N, Rogier O, Russo B, Hippolyte L, Hadwin J et al (2013). It's all in the eyes: subcortical and cortical activation during grotesqueness perception in autism. PloS One 8: e54313. 